\title{
Design of reinforced cohesive soil walls accounting for wall facing contribution to stability
}

\author{
YARA BARBOSA FRANCO*, STEFANO UTILI $\dagger$ and JEFFERSON LINS DA SILVA $\$$
}

\begin{abstract}
Where granular materials are not easily available, local cohesive soils are increasingly employed in geosynthetic reinforced soil walls as a cheap and sustainable option. Conventional design methods do not yet account for the beneficial effect of cohesion in reducing the amount of required reinforcement. Similarly, the contribution of the face to stability is rarely accounted for, despite plenty of experimental evidence in its favour. In this paper, a semi-analytical method based on limit analysis is developed for the design of reinforced soil walls in frictional-cohesive backfills accounting for the wall contribution. A parametric analysis was conducted to evaluate the effect of soil cohesion and friction angle, facing batter, block width, location of the reaction force acting on the face, facing-backfill interface friction, facing-foundation interface friction and reinforcement length. Dimensionless design charts providing the required amount of reinforcement for lengths recommended in design standards are provided for both uniform and linearly increasing reinforcement distributions. It emerges that accounting for the presence of cohesion and the facing element can lead to significant savings in the overall level of reinforcement, and that tension cracks can be particularly detrimental to wall stability for highly cohesive soils so they cannot be overlooked in the design.
\end{abstract}

KEYWORDS: cohesive soils; design; geosynthetics; reinforced soils; upper bound limit analysis

\section{INTRODUCTION}

Facing elements in reinforced soil structures traditionally are employed for aesthetic reasons and for protection against backfill erosion. Varied facing types are available, such as segmental precast concrete panels, dry cast modular block wall units, welded wire mesh, gabion facing and geosynthetic facing. These facing elements are accounted for when performing numerical analysis of reinforced soil wall systems by the finite-element method (FEM) or finite-difference method (FDM). However, conventional design methodologies, such as methods based on limit equilibrium and analytical methods, ignore the potential contribution of the face to the system's performance (Berg et al., 2009; NCMA, 2010; Aashto, 2017). Nevertheless, plenty of works have recognised that a hard facing element associated with toe restraint may contribute to a structure's stability.

To evaluate the influence of the facing type on wall behaviour, large-scale tests (height of $3.6 \mathrm{~m}$ ) were performed by Bathurst (1993), with an incremental panel and a full-height facing, and by Bathurst et al. (2006), with a dry-stacked modular concrete block facing and a wrapped facing. The reinforced soil wall models were backfilled with sand material and loaded in stages up to failure. Ehrlich \& Mirmoradi (2013) evaluated the effects of facing stiffness and

Manuscript received 13 December 2020; revised manuscript accepted 30 July 2021.

Discussion on this paper is welcomed by the editor.

Published with permission by the ICE under the CC-BY 4.0 license. (http://creativecommons.org/licenses/by/4.0/)

* Department of Geotechnical Engineering, São Carlos School of Engineering-University of São Paulo, São Paulo, Brazil (Orcid:0000-0002-5749-7754).

$\dagger$ School of Engineering, Newcastle University, Newcastle upon Tyne, UK (Orcid:0000-0003-3156-8013).

$\ddagger$ Department of Geotechnical Engineering, São Carlos School of Engineering-University of São Paulo, São Paulo, Brazil

(Orcid:0000-0002-2226-4950). toe resistance with block and wrapped facing types and sand as the backfill material. The reduced $1.5 \mathrm{~m}$ high models were surcharged in stages up to $100 \mathrm{kPa}$ and the wall behaviour was investigated as a function of facing properties. In other studies, the influence of toe restraint was evaluated in centrifuge tests with reinforced sand (Zhang et al., 2019) and the facing contribution to seismic response was studied in reduced-scale tests under cyclic loading (shaking table test) (El-Emam \& Bathurst, 2005).

Numerical studies with FEM and FDM have been conducted mainly for working stress conditions, without surcharge loading, and with sand as backfill material. Parametric analyses have been performed to evaluate the influence of different parameters, such as the influence of wall facing parameters. Ho \& Rowe (1996) evaluated, among other factors, the effect of toe restraint in reinforcement loads with continuous full panel facing, showing that for shorter walls the toe attracts a larger portion of the load, thus reducing the reinforcement load. The effect of modular block facing properties on wall behaviour was studied by Ling \& Leshchinsky (2003), who showed that block width influences wall displacements, geosynthetic loads and lateral earth pressures at the facing, whereas varying the interface friction between blocks has a negligible effect on wall behaviour. Huang et al. (2010) investigated the influence of toe restraint on the behaviour of reinforced soil with modular block facing by varying the horizontal toe stiffness. They found that the wall toe can significantly contribute to the stability of the structure under working stress conditions. Similarly, Mirmoradi \& Ehrlich (2015) investigated the influence of facing stiffness and two different toe conditions: free base and fixed base. They showed that the combined effect of those factors can have a significant influence on reinforcement load, especially in the layers close to the bottom of the wall.

Nevertheless, studies that aim to quantify and incorporate the facing contribution explicitly in the design are scarce. Previous studies have been conducted in the framework of limit equilibrium (Leshchinsky et al., 1995, 2010, 2017; 
Ismeik \& Guler, 1998) and of analytical methods (Xie et al., 2016), but they are all restricted to cohesionless soils. Some recent studies have focused on improving the selection of the reinforcement layout, through optimisation techniques (González-Castejón \& Smith, 2021) or through visual tools such as safety maps with consideration of the facing (Leshchinsky et al., 2017), but without accounting for the effect of cohesion nor tension cracks on the wall's stability.

The conservative assumption of neglecting cohesion in design can be attributed to the fact that geosynthetics were initially conceived for cohesionless granular soils and that the first design guidelines published for geosynthetic reinforced earth structures disregard the beneficial effect of cohesion for example, the American Association of State Highway and Transportation Officials (Aashto) and Jewell (1996). However, the recent editions of the Aashto LRFD bridge design specifications (Aashto, 2012, 2017) allow for the inclusion of cohesion in the seismic design of geo-reinforced slopes, although unfortunately no formulae are provided for this purpose. The Aashto revisit was prompted by the work of Anderson et al. (2008) which, for example, shows that an amount of cohesion as much as $10 \mathrm{kPa}$ can reduce the thrust against an earth structure by up to $50-75 \%$ for typical design conditions. In light of these findings, Vahedifard et al. (2014: p. 04014016-4 J) investigated the beneficial effect of cohesion on geosynthetic-reinforced earth structures based on limit equilibrium, concluding that the results clearly demonstrate the significant impact of cohesion on the $K_{\mathrm{ae}}$ value' ( $K_{\mathrm{ae}}$ being an approximate estimate of the design seismic active earth pressure coefficient). One of the objectives of this paper is to provide an analytical model for the design of reinforced soil walls in cohesive soils accounting for the positive contribution of both facing elements and soil cohesion.

Cohesive soils manifest limited, if not negligible, tensile strength so they are subject to the formation of cracks (Porbaha \& Goodings, 1997; Thusyanthan et al., 2007). Tension cracks forming in geo-reinforced slopes have been reported in experiments in geotechnical centrifuges (Porbaha \& Goodings, 1997; Suah \& Goodings, 2001) and in post-earthquake field observations (Ling et al., 2001). Moreover, Baker (1981), Michalowski (2013), Utili (2013) and Utili \& Abd (2016), when investigating the stability of uniform cohesive frictional $(c-\phi)$ slopes, concluded that when the presence of cracks is neglected, slope stability may be significantly overestimated. The same conclusions were reached by Abd \& Utili (2017) for the case of $c-\phi$ geo-reinforced slopes. Therefore, the presence of tension cracks must be accounted for to achieve a safe design. Porbaha et al. (2000) and Chen et al. (2018) evaluated the case of cohesive soil-retaining structures, disregarding the presence of facing elements and tension cracks, whereas Chehade et al. (2019) accounted for tension cracks but not the facing contribution.

In the present paper, first the stabilising effect of facing elements is included in the analytical method presented by Abd \& Utili (2017) to design geosynthetic-reinforced backfills in cohesive soils. This is achieved by explicitly accounting for the facing weight to estimate the toe load capacity. Second, a novel solution scheme is implemented to evaluate all possible combinations of failure mechanisms (soil shear failure with reinforcement rupture and pullout) and a prescribed reinforcement length. Failure mechanisms emerging at the wall facing are included in the analyses. Third, the analytical model here proposed is used to produce dimensionless design charts ready to use for practitioners. Finally, it will be shown that the facing element may have a significant influence in reducing the reinforcement needed and, possibly, decreasing the over-conservatism in the design of reinforced soil structures. To the best of the authors' knowledge, this is the first time that both the facing element and backfill cohesion, while considering the presence of tension cracks, are accounted for in the design of reinforced walls.

\section{ASSUMPTIONS MADE IN THE ANALYTICAL METHOD}

There are two main approaches to investigating the stability of geosynthetics-reinforced structures: one where the local equations of equilibrium for an equivalent continuum formed by ground and reinforcement together are derived by way of homogenisation techniques (e.g. Sawicki, 1983; Buhan et al., 1989), termed the continuum approach by Michalowski \& Zhao (1995), and another one, to be used here, where ground and geo-reinforcement are considered as two separate structural components, called the structural approach (Michalowski \& Zhao, 1995).

In this paper, the structural approach will be employed together with the kinematic (upper bound) method of limit analysis (LA) assuming a rigid rotational mechanism to obtain lower bounds on the required level of reinforcement. This means the calculated levels of reinforcement are smaller than the values required to avoid collapse. However, numerical analyses run by Abd \& Utili (2017) for the case of geo-reinforced slopes in $c-\phi$ soils without facing elements show that the lower bounds on the reinforcement strength found by assuming a rigid rotational mechanism as here are very close to upper bounds obtained by numerical finite-element limit analysis (FELA) (Sloan, 2013), with the difference between them being lower than 14\% for any value of cohesion considered. Hence, true collapse values were determined with an accuracy of $\pm 7 \%$ by taking the average of the two bounds. Also, finite-element displacement-based analyses with shear strength reduction technique were performed by Abd \& Utili (2017), assuming the validity of the normality rule consistent with the theory of limit analysis. These provided values of reinforcement very close to the lower bounds found by the kinematic method of limit analysis assuming a rigid rotational mechanism.

Note that limit analysis assumes a simplified constitutive behaviour for both ground and reinforcement (i.e. rigidperfectly plastic) and the validity of the normality rule (that is, associated plastic flow), which at rigour does not hold true for most soils. The authors acknowledge that for a drained stability analysis involving soils with high friction angles, the use of an associated flow rule predicts excessive dilation during shear failure, and raises the question of whether the bound theorems will provide realistic estimates of the limit load. Already in the pioneering investigation of this issue, Davis (1968) argued that the flow rule will not have a major influence on the limit load for frictional soils unless the problem is strongly constrained in a kinematic sense. A precise definition of the degree of kinematic constraint is elusive, but the problem is not strongly constrained, since it involves a freely deforming upper ground surface and a semi-infinite domain. For these cases, Davis (1968) conjectured that it is reasonable to assume that the bound theorems will give acceptable estimates of the true limit load. More recently, Muraro et al. (2015: p. 510) performed displacement-based FEM analyses of the active thrust upon retaining walls showing 'soil dilatancy has negligible effects on the stability of the wall'. Also, Potts \& Fourie (1986) found that the dilation angle has very little influence on soil pressure for a retaining wall with a horizontal ground surface.

In the stability charts produced in the literature for slopes in cohesive soils two scenarios of tension cracks have been 
considered so far: cracks pre-existing shear failure (Utili, 2013) and cracks forming simultaneously with the shear failure surface (Michalowski, 2013). Here cracks are assumed to pre-exist the formation of the shear log-spiral failure since there is abundant experimental evidence showing that crack formation in cohesive soils is a brittle phenomenon (e.g. Thusyanthan et al., 2007), unlike the log-spiral part of the slope failure mechanism where failure is in shear and ductile. This implies that stress redistribution can be assumed only along the log-spiral part of the mechanism, with the crack to be assumed opened by the time the progressive ductile failure along the log-spiral part of the mechanism reaches the crack. Therefore, in the energy balance equation employed for the derivation of the analytical solution (see section entitled 'Derivation of the semi-analytical solution') it was assumed that no energy is dissipated by crack formation.

The assumption of an open crack implies the solution is independent of the amount of soil tensile strength. Of course, the depth of tension cracks is dependent on the amount of soil tensile strength and of tensile stresses arising in the backfill, with crack depth being dictated by the extent of the region where tensile stresses exceed the soil tensile strength. This means one would expect the ground tensile strength to be related to the depth of the tension cracks and so in turn to the amount of reinforcement prescribed by the solution. But the very onset of a crack changes the stress distribution so that complex FEM numerical modelling and constitutive equations are required to mimic crack propagation to discover the link between crack depth and ground tensile strength. In this paper, consistently with the limit analysis kinematic approach, the crack is a geometric boundary condition for the potential failure mechanism considered. Among all the potential failure mechanisms, with each potential mechanism involving a crack of a specific depth and location, the critical failure mechanism is found as a worst-case scenario - that is, the mechanism that gives rise to the lowest stability factor. So, the crack (depth and location) that has the most adverse effect on stability is found as a result. This assumption errs on the safe side since the actual crack depth may be less than the depth of the crack associated with the worst-case scenario, depending on the actual distribution of the tensile stresses in the backfill and of the ground tensile strength.

The amount of cohesion that can be relied upon in the design of backfills made of $c-\phi$ soils depends on several factors that vary over time; to name a few, these include: the ground moisture content; the level of the phreatic line in the backfill; and the intended design lifetime for the reinforced wall, since this has implications on the weather-induced deterioration the soil strength is likely to experience over time. Several publications deal with the choice of the values for $c$ for clay soils, with the use of peak strength, residual strength, operational strength (Potts et al., 1997) and critical state strength advocated depending on the geotechnical problem tackled. The choice of the value for cohesion is outside the scope of this paper. Take \& Bolton (2011) provide a good coverage of the literature with regard to such a choice for clay slopes. Here, it is enough to recall that the designer must be careful to design the reinforcement considering the worst-case scenario in terms of hydraulic conditions that can occur over the entire lifetime of the structure and adopting a cautious approach.

It is important to note that even in the case of soils possessing no true cohesion - that is, exhibiting zero shear strength at zero confinement - their shear strength can still be suitably described by the failure criterion adopted here (see Fig. 1). In this case $c$ is to be interpreted as an apparent cohesion with the strength envelope intercepting the $\tau$ axis at the origin.

\section{DESCRIPTION OF THE PROBLEM}

According to Bathurst et al. (1993a) typical facing batters, $\beta$, are in the range of $75-87^{\circ}$ for geosynthetic-reinforced structures. Therefore, in the present work, the authors considered uniform $c-\phi$ reinforced soil walls with facing batters between $70^{\circ}$ and $90^{\circ}$. A homogeneous backfill without external surcharge is here assumed for the sake of simplicity. However, an external surcharge can be added to the calculations in a straightforward way.

Two reinforcement distributions were considered

(a) a uniform distribution (UD): reinforcement layers of equal strength, equally spaced (Fig. 2(a))

(b) a linearly increasing distribution (LID): reinforcement layers with decreasing vertical spacing and increasing strength over depth (Fig. 2(b)).

The expressions for the reinforcement strength distribution over depth for the UD and LID cases, respectively, are

$$
\begin{aligned}
& K_{\mathrm{t}}=\frac{N T}{H} \\
& K=2 K_{\mathrm{t}} \frac{(H-y)}{H}
\end{aligned}
$$

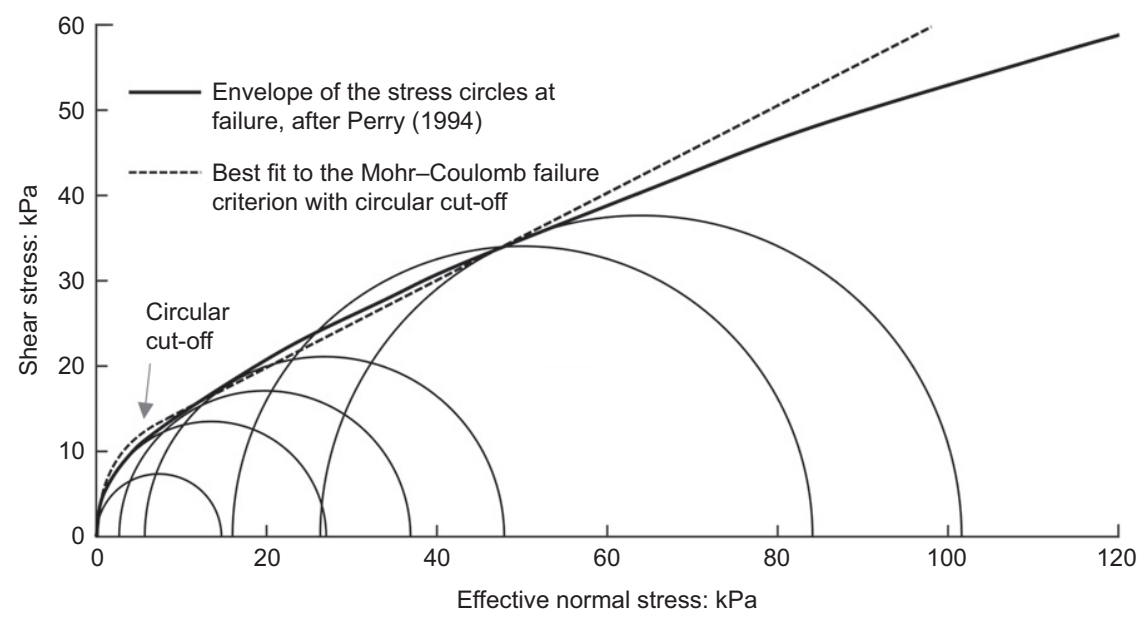

Fig. 1. Shear strength of London Clay achieved from drained compressive triaxial tests at low stresses: non-linear envelope (solid curve) of the stress circles at failure (after Perry, 1994); linear $c-\phi$ best fit with tension cut-off (dashed curve) 


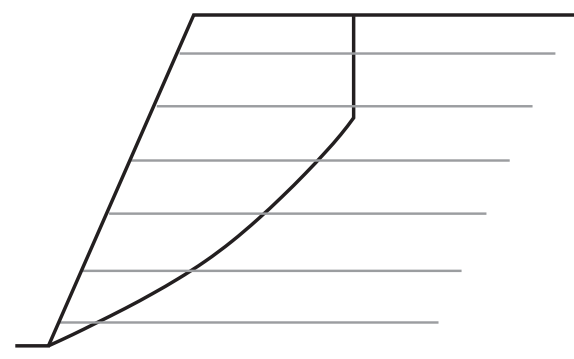

(a)

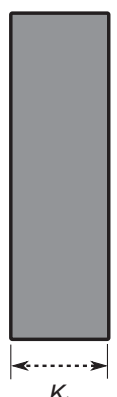

$K_{\mathrm{t}}$

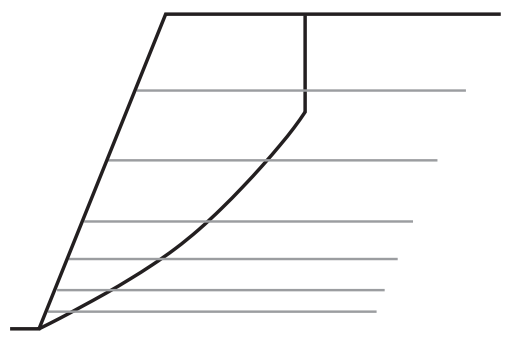

(b)

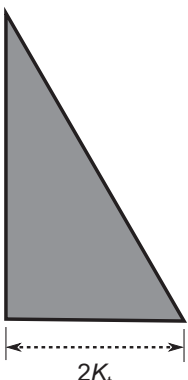

$2 K_{\mathrm{t}}$

Fig. 2. Geosynthetic reinforcement layouts: (a) uniform distribution; (b) linearly increasing distribution with depth

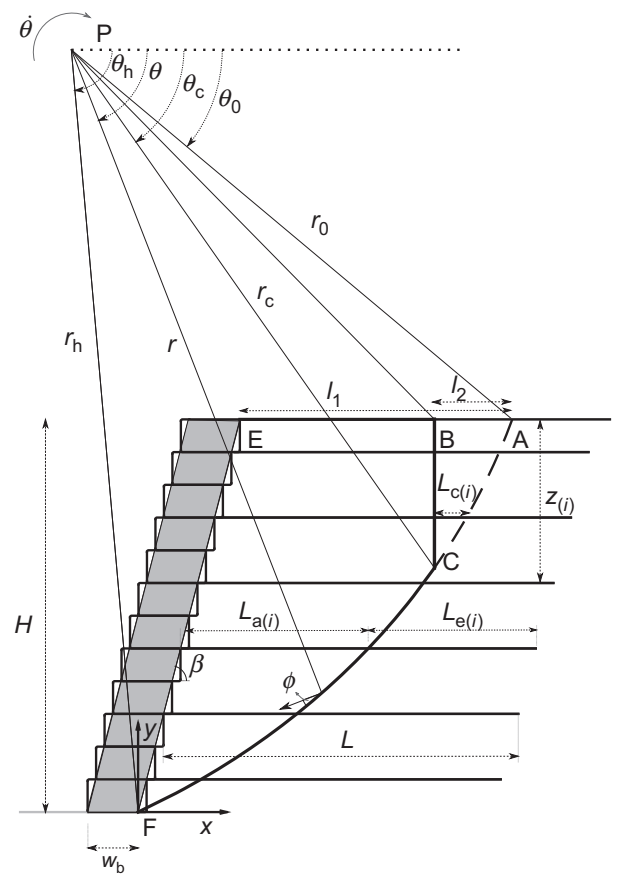

Fig. 3. Rotational failure mechanism in a reinforced soil wall with a vertical crack and the relevant notation. Two types of wall facing are considered: modular block facing and full-height rigid facing (in grey)

where $K_{\mathrm{t}}$ is the average strength of reinforcement in the reinforced soil wall; $K$ is the local reinforcement strength for LID distribution; $N$ is the number of reinforcement layers; $T$ is the strength of a single layer at yielding point; $H$ is the wall height; and $y$ is the vertical upward coordinate departing from the wall toe.

A log-spiral failure mechanism with a vertical tension crack is assumed here, a kinematically admissible failure surface in limit analysis (Fig. 3). In this mechanism, all deformations occur along the log-spiral $\mathrm{F}-\mathrm{C}$, with no energy dissipation accounted for the brittle opening of the tension crack B-C.
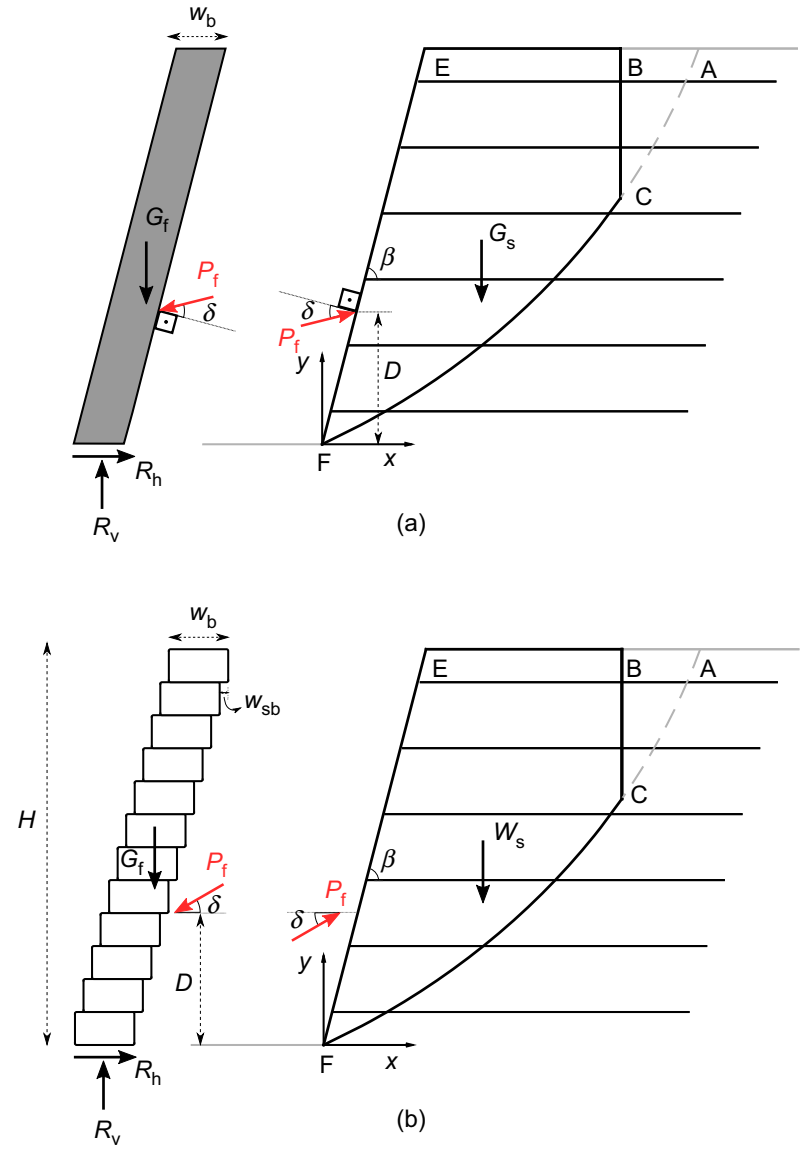

Fig. 4. Free-body diagram of the facing element: (a) conventional direction; (b) modified direction

In this paper, tensile failure and combined failure are evaluated. The former assumes that all layers fail in tensile rupture and that the reinforcement length is sufficiently long to mobilise its tensile strength. In combined failure, some layers fail in tensile rupture while others fail by pullout, including also the possibility of compound failure (some layers are bypassed by the failure surface). A third possible failure mechanism is direct sliding over one reinforcement layer (Michalowski, 1997), but this is not addressed in the present study.

Two types of wall facing are considered here, a continuous facing and a modular stacked block facing. The way in which the authors treat the direction of the resultant force acting at the wall differentiates them. For the continuous facing, the direction used for conventional retaining structures was adopted, with the resultant reaction force inclined at an angle $\delta$ with the perpendicular to the facing batter, with $\delta$ being the interface friction angle between the continuous face and the retained soil (Fig. 4(a)). This facing system is representative of the widely used full-height rigid facing in Japan (Tatsuoka et al., 1998). For the second facing, with discrete blocks, a modified direction for the resultant was assumed (Fig. 4(b)) that accounts only for the friction along the vertical interfaces between blocks and retained soil (Leshchinsky et al., 2012; Vahedifard et al., 2014; Xie et al., 2016).

\section{DERIVATION OF THE SEMI-ANALYTICAL SOLUTION}

Abd \& Utili (2017) added the effect of cohesion and the presence of tension cracks to the formulation presented by Michalowski (1997) for cohesionless soils. However, their 
study was restricted to reinforced soil slopes, with no facing element. In the formulation presented here, the presence of a retaining wall is added.

The assumed failure surface is described by the following log-spiral expression

$$
r=r_{0} \exp \left[\tan \phi\left(\theta-\theta_{0}\right)\right]
$$

where $\theta$ and $\theta_{0}$ are the angles made by $r$ and $r_{0}$, respectively, with the horizontal; $r$ is the distance between the spiral centre (point $\mathrm{P}$ ) and a generic point on the log-spiral slip surface; and $r_{0}$ is the length of line PA in Fig. 3.

The energy balance equation is given by

$$
\dot{D}=\dot{W}
$$

where $\dot{D}$ is the internal energy dissipation rate and $\dot{W}$ is the external work rate.

In the following, the case of failure of all reinforcements is first examined, which implies that the geosynthetic length is sufficiently long to develop the load corresponding to its tensile strength. In the sequence, the case of a fixed reinforcement length is evaluated, based on minimal length recommendations of various design standards (Berg et al., 2009; BSI, 2010, NCMA, 2010; Aashto, 2017), with a combined mode of failure (pullout and tensile failure). This second approach, with a predefined length, may lead to larger values for the required reinforcement strength than the one obtained with the failure of all layers. Nonetheless, it allows the designer to evaluate whether the cost savings achieved by shortening the reinforcement length would be sufficient to offset the needed increase in strength. Since the reinforcement length directly affects the volume of soil backfill, its reduction may have a significant impact on the overall cost of the structure. In fact, the main cost savings that can be realised by employing cohesive soils as backfill are due to reduced backfill volume and the use of local, less expensive materials.

All the Matlab source codes developed are provided in the online supplementary material for the paper.

\section{Required reinforcement strength}

The limit analysis formulation considers the wall at imminent collapse with the soil-reinforcement system behaving as a rigid-perfectly plastic body. Each reinforcement layer is assumed to be at yield and a sufficient anchorage length is assumed to be present.

The internal energy dissipation comes from the reinforcement $\left(\dot{D}_{\mathrm{r}}\right)$ and the soil $\left(\dot{D}_{\mathrm{s}}\right)$ along the crack (B-C in Fig. 3$)$ and along the log-spiral failure surface $(\mathrm{C}-\mathrm{F}$ in Fig. 3). For a cohesionless soil the latter term is null. The external work is done by the soil self-weight $\left(\dot{W}_{\mathrm{s}}\right)$, any pore-water pressure in the ground $\left(\dot{W}_{\mathrm{w}}\right)$ and the wall facing contribution $\left(\dot{W}_{\mathrm{f}}\right)$. The term $\dot{W}_{\mathrm{s}}$ is calculated as the work of block E-F-A minus the work of block B-C-A (Fig. 3). The work of block E-F-A and the work of block $\mathrm{B}-\mathrm{C}-\mathrm{A}$ are calculated by the algebraic summation of the work of blocks $\mathrm{P}-\mathrm{F}-\mathrm{A}, \mathrm{P}-\mathrm{E}-\mathrm{A}$ and $\mathrm{P}-\mathrm{F}-\mathrm{E}$ (Chen, 1975) and of blocks $\mathrm{P}-\mathrm{C}-\mathrm{A}, \mathrm{P}-\mathrm{B}-\mathrm{A}$ and $\mathrm{P}-\mathrm{C}-\mathrm{B}$ (Utili \& Nova, 2007; Utili, 2013), respectively. Therefore, equation (4) can be re-written as

$$
\dot{D}_{\mathrm{r}(\mathrm{B}-\mathrm{C})}+\dot{D}_{\mathrm{s}(\mathrm{C}-\mathrm{F})}+\dot{D}_{\mathrm{r}(\mathrm{C}-\mathrm{F})}=\dot{W}_{\mathrm{s}}+\dot{W}_{\mathrm{w}}+\dot{W}_{\mathrm{f}}
$$

where

$$
\begin{aligned}
\dot{D}_{\mathrm{s}(\mathrm{C}-\mathrm{F})} & =c \dot{\theta} r_{0}^{2} \exp \left[2 \tan \phi\left(\theta_{\mathrm{C}}-\theta_{0}\right)\right] \frac{\exp \left[2 \tan \phi\left(\theta_{\mathrm{h}}-\theta_{\mathrm{C}}\right)-1\right]}{2 \tan \phi} \\
& =c \dot{\theta} r_{0}^{2} g_{\mathrm{s}}\left(\theta_{0}, \theta_{\mathrm{h}}, \theta_{\mathrm{C}}, \phi\right)
\end{aligned}
$$

$$
\begin{aligned}
\dot{D}_{\mathrm{r}(\mathrm{B}-\mathrm{F})} & =\dot{D}_{\mathrm{r}(\mathrm{B}-\mathrm{C})}+\dot{D}_{\mathrm{r}(\mathrm{C}-\mathrm{F})} \\
& =\frac{1}{2} K_{\mathrm{t}} \dot{\theta} r_{0}^{2}\left\{\exp \left[2 \tan \phi\left(\theta_{\mathrm{h}}-\theta_{0}\right)\right] \sin ^{2} \theta_{\mathrm{h}}-\sin ^{2} \theta_{0}\right\} \\
& =K_{\mathrm{t}} \dot{\theta} r_{0}^{2} g_{\mathrm{r}}\left(\theta_{0}, \theta_{\mathrm{h}}, \phi\right)
\end{aligned}
$$

$$
\begin{aligned}
\dot{W}_{\mathrm{s}} & =\dot{W}_{1}-\dot{W}_{2}-\dot{W}_{3}-\left(\dot{W}_{4}-\dot{W}_{5}-\dot{W}_{6}\right) \\
& =\gamma \dot{\theta} r_{0}^{3}\left(f_{1}-f_{2}-f_{3}-f_{4}+f_{5}+f_{6}\right) \\
\dot{W}_{\mathrm{w}} & =\gamma \dot{\theta} r_{0}^{3} r_{\mathrm{u}} f_{\mathrm{w}}
\end{aligned}
$$

Equation (7) is related to the case of uniform distribution of reinforcement (UD). The correspondent expressions for the case of linear distribution (LID) are reported in Appendix 1. Abd \& Utili (2017) have shown that $\dot{D}_{\mathrm{r}(\mathrm{A}-\mathrm{C})}=$ $\dot{D}_{\mathrm{r}(\mathrm{B}-\mathrm{C})}$ and therefore the energy dissipated by the reinforcement can be expressed solely by equation (7). In this paper it is advocated that crack formation, unlike the ductile formation of the log-spiral $\mathrm{F}-\mathrm{C}$, is a brittle phenomenon, and therefore the energy dissipated by crack formation should not be accounted for in limit analysis, so $\dot{D}_{\mathrm{s}(\mathrm{B}-\mathrm{C})}=0$.

The terms $f_{1}, f_{2}, f_{3}, f_{4}, f_{5}, f_{6}$ and $f_{\mathrm{w}}$ are non-dimensional functions dependent on the failure surface geometry $\left(\theta_{0}, \theta_{\mathrm{h}}, \theta_{\mathrm{C}}, \beta\right), \gamma$ is the soil unit weight, $\dot{\theta}$ is the angular velocity of the sliding soil mass and $\phi$ is the soil internal friction angle. Their analytical expressions are reported in Appendix 2 of this paper.

The work rate done by the reaction force acting on the facing element $\left(P_{\mathrm{f}}\right)$ is calculated as the scalar product of this force and the velocity at its point of action, which can be expressed as

$$
\dot{W}_{\mathrm{f}}=-\dot{\theta} r_{0} P_{\mathrm{f}} f_{7}
$$

where $f_{7}$ is a non-dimensional function provided by Li \& Yang (2019) for the conventional direction of the thrust (Fig. 4(a)) and by Xie et al. (2016) for the modified direction (Fig. 4(b)). Their full expressions are reported in Appendix 2.

Note that $P_{\mathrm{f}}$ is negative since it acts to stabilise the system. The stabilising effect of adhesive forces at the soil-wall interface is neglected, erring on the conservative side.

By isolating the facing element in Fig. 3 and calculating its rigid body equilibrium, $P_{\mathrm{f}}$ can be determined (Fig. 4). Note that the horizontal force acting at the wall toe in general stems from the passive resistance mobilised in front of the embedded face and friction between the base of the first block and the foundation soil. However, American public and private design guidelines such as Aashto LRFD bridge design specification (Aashto, 2017) and the National Concrete Masonry Association (NCMA) Design manual for segmental retaining walls (NCMA, 2010) do not recommend relying on the passive earth pressures for the stability of either unreinforced or reinforced soil structures, since this is hard to guarantee throughout the service life of the structure. Similarly, British standard BS 8006: Code of practice for strengthened/reinforced soils and other fills (BSI, 2010) recommends to neglect passive earth pressures acting on the wall toe for external stability calculations. Hence, here only the frictional contribution was considered, consistently with Leshchinsky et al. (2010).

Leshchinsky et al. (2012) argue that interface friction mobilisation between the horizontal setbacks of the blocks ( $w_{\mathrm{sb}}$ in Fig. 4(b)) and soil is likely to be partial, so it cannot be relied upon. Assuming full mobilisation would imply a 
questionable upward normal force acting along the horizontal interface. Therefore, as in Leshchinsky et al. (2012), the forces exchanged under the block setbacks are ignored and only the vertical block faces are assumed to be in contact with the fill. This assumption is appropriate for the case of inclined segmental block facing. In this case, the resultant reaction force assumes the direction depicted in Fig. 4(b), inclined at an angle $\delta$ with the horizontal. This direction is identified here, as in Vahedifard et al. (2014), as the modified direction and has been adopted previously by Xie et al. (2016) and Vahedifard et al. (2014) for the case of reinforced soil walls with segmental blocks. The so-called conventional direction by Vahedifard et al. (2014), shown in Fig. 4(a), refers to the usual direction adopted for stability problems of conventional retaining structures, with a continuum facing.

The location of $P_{\mathrm{f}}$, marked as $D$ in Fig. 4, may depend on some factors such as the toe restraint conditions and wall height. Indeed, the effect of toe restraint is more significant for shorter walls, for which the dimensions of the blocks relative to the wall height can have a significant influence on wall stability (Leshchinsky, 2007). For higher structures, the toe restraint influence is usually limited to the lower section of the wall (Holtz \& Lee, 2002; Mirmoradi \& Ehrlich, 2015).

Considering the interface friction angle between the face and wall base (usually a levelling pad) or between the levelling pad and the foundation soil (whichever is smaller) equal to $\delta_{\text {base }}$ and the interface friction angle $\delta$ between the reinforced soil and the back of the wall, $P_{\mathrm{f}}$ can be calculated from the rigid body equilibrium of the facing as (conventional direction)

$$
P_{\mathrm{f}}=\frac{G_{\mathrm{f}} \tan \delta_{\text {base }}}{\cos (\delta+\beta-\pi / 2)-\sin (\delta+\beta-\pi / 2) \tan \delta_{\text {base }}}
$$

where $G_{\mathrm{f}}$ is the face self-weight.

For the modified direction (case of stacked blocks), $P_{\mathrm{f}}$, is given by

$$
P_{\mathrm{f}}=\frac{G_{\mathrm{f}} \tan \delta_{\text {base }}}{\cos \delta-\sin \delta \tan \delta_{\text {base }}}
$$

Downdrag forces contribute to the stability of the system by summing up to the facing weight and composing the normal force acting at the wall base. However, design such as NCMA (2010) suggests ignoring the downdrag forces $\left(P_{\mathrm{f}} \sin \delta\right.$ in Fig. 4), owing to the difficulty of compaction near the face and the unpredictability of the normal force acting on the vertical segments of the blocks (Leshchinsky et al., 2010). Therefore, disregarding downdrag forces, to be conservative, leads to simpler expressions for equations (11) and (12)

$$
\begin{aligned}
& P_{\mathrm{f}}=\frac{G_{\mathrm{f}} \tan \delta_{\text {base }}}{\cos (\delta+\beta-\pi / 2)} \\
& P_{\mathrm{f}}=\frac{G_{\mathrm{f}} \tan \delta_{\text {base }}}{\cos \delta}
\end{aligned}
$$

Note that downdrag forces may also arise from the hanging of reinforcement layers at the facing connections, which occurs when the reinforced soil settles more than the facing element. These are difficult to predict but can provide a significant contribution to the wall's stability, especially for full-height rigid facing with high connection strengths (Leshchinsky et al., 2010; Damians et al., 2013).

The face self-weight is calculated as the sum of the weight of all blocks, for the stacked block facing case

$$
G_{\mathrm{f}}=N_{\mathrm{b}} h_{\mathrm{b}} \gamma_{\mathrm{b}} w_{\mathrm{b}}=H \gamma_{\mathrm{b}} w_{\mathrm{b}}
$$

where $N_{\mathrm{b}}, \gamma_{\mathrm{b}}, w_{\mathrm{b}}$ and $h_{\mathrm{b}}$ are the total number of blocks, the block unit weight and the block width (toe to heel) and height, respectively; $H$ is the wall height. The wall height comes assuming the full height of the dry-stacked block contributing to toe load capacity.

For facing batters $\beta<82^{\circ}$, the hinge height approach is recommended in some design manuals (Berg et al., 2009; Aashto, 2017) to estimate the normal stress transmitted between dry-stacked block facing units. This would limit the maximum design weight of the units that can be transferred to the wall base. However, studies considering an unyielding foundation have shown that this is an overly conservative assumption, since downdrag forces at the interface between the soil and the face result in vertical toe loads higher than the facing self-weight (Bathurst \& Walters, 2000; Hatami \& Bathurst, 2005). This has prompted the 3rd edition of the NCMA design manual (NCMA, 2010) to remove consideration of the hinge height entirely, even for facing batters up to $70^{\circ}$. For this reason, the full height of the wall is used here to estimate the toe capacity.

Defining the angle of $P_{\mathrm{f}}$ with respect to the horizontal as $\delta_{\mathrm{h}}=\delta+\beta-\pi / 2$ for the conventional force direction and $\delta_{\mathrm{h}}=\delta$ for the modified force direction, and substituting equation (15) into equation (11) or into equation (12), the following expression is obtained after normalisation by $\gamma H^{2}$

$$
\frac{P_{\mathrm{f}}}{\gamma H^{2}}=\frac{\left(\gamma_{\mathrm{b}} / \gamma\right)\left(w_{\mathrm{b}} / H\right) \tan \delta_{\text {base }}}{\cos \delta_{\mathrm{h}}-\sin \delta_{\mathrm{h}} \tan \delta_{\text {base }}}
$$

By substituting the energy rate contributions calculated through equations (6)-(10) into equation (5) it is possible to obtain the objective function that allows determination of the minimum level of reinforcement required (lower bound)

$$
\begin{aligned}
\frac{K_{\mathrm{t}}}{\gamma H}= & \frac{\left(f_{1}-f_{2}-f_{3}-f_{4}+f_{5}+f_{6}+r_{\mathrm{u}} f_{\mathrm{w}}\right)}{\left(H / r_{0}\right)\left(g_{\mathrm{r}}\right)}-\left(\frac{c}{\gamma H}\right)\left(\frac{g_{\mathrm{s}}}{g_{\mathrm{r}}}\right) \\
& -\left(\frac{H}{r_{0}}\right) \frac{P_{\mathrm{f}}}{\gamma H^{2}} \frac{f_{7}}{\left(g_{\mathrm{r}}\right)} \\
\frac{K_{\mathrm{t}}}{\gamma H}= & f\left(\theta_{0}, \theta_{\mathrm{h}}, \theta_{\mathrm{C}}, \beta, r_{\mathrm{u}}, \phi, c / \gamma H, \delta, D, w_{\mathrm{b}} / H, \delta_{\text {base }}\right)
\end{aligned}
$$

\section{Length of reinforcement}

The minimum length of reinforcement is calculated by considering a combined failure mechanism, involving pullout of some layers and rupture of others. Compound failure mechanisms where the failure surface extends into the unreinforced soil zone are taken into account as well. In these cases, the remaining crossed layers can fail by pullout, by tension or a combination of both.

Assuming layers of equal length, the normalised length of reinforcement $(L / H)$ is given by

$$
\frac{L}{H}=\frac{L_{\mathrm{e}(i)}}{H}+\left(\frac{L_{\mathrm{a}(i)}}{H}-\frac{L_{\mathrm{c}(i)}}{H}\right)
$$

where $L_{\mathrm{e}(i)} / H$ is the effective (or anchorage) length of reinforcement layer $i$ yet to be calculated; $\theta_{(i)}$ is the angle related to the intersection between the failure surface and layer $i ; L_{\mathrm{a}(i)} / H$ is the reinforcement length of layer $i$ in the active zone up to the failure surface; and $L_{\mathrm{c}(i)} / H$ is the part of the anchorage length of the reinforcement spared because of the crack (see Fig. 3). 
Trigonometry dictates that

$$
\begin{aligned}
\frac{L_{\mathrm{a}(i)}}{H}= & -\left(\cos \theta_{\mathrm{h}}+\sin \theta_{\mathrm{h}} \cot \beta\right) \frac{r_{0}}{H} \exp \left[\tan \phi\left(\theta_{\mathrm{h}}-\theta_{0}\right)\right] \\
& +\left(\cos \theta_{(i)}+\sin \theta_{(i)} \cot \beta\right) \frac{r_{0}}{H} \exp \left[\tan \phi\left(\theta_{(i)}-\theta_{0}\right)\right]
\end{aligned}
$$

For reinforcement layers crossing the crack, $L_{\mathrm{c}(i)} / H$ is calculated by
Equation (21) can be re-written by substituting $L_{\mathrm{e}(i)} / H$ given in equation (18) so the required reinforcement is given as a direct function of $L / H$

$$
\begin{aligned}
\frac{K_{\mathrm{t}}}{\gamma H}= & \frac{\left(r_{0} / H\right)^{2}\left(f_{1}-f_{2}-f_{3}-f_{4}+f_{5}+f_{6}+r_{\mathrm{u}} f_{\mathrm{w}}\right)-\left(r_{0} / H\right)(c / \gamma H)\left(g_{\mathrm{s}}\right)}{1 / N\left\{\sum_{\text {rupture }}\left[\sin \theta_{0}+\left(z_{(i)} / r_{0}\right)\right]\right\}} \\
& +\frac{\left(P_{\mathrm{f}} / \gamma H^{2}\right) f_{7}-2 f_{\mathrm{b}} \tan \phi\left(1-r_{\mathrm{u}}\right)\left(C_{1} L / H-C_{2}\right)}{1 / N\left\{\sum_{\text {rupture }}\left[\sin \theta_{0}+\left(z_{(i)} / r_{0}\right)\right]\right\}}
\end{aligned}
$$

$$
\frac{L_{\mathrm{c}(i)}}{H}=\frac{r_{0}}{H}\left\{\exp \left[\tan \phi\left(\theta_{(i)}-\theta_{0}\right)\right] \cos \theta_{(i)}-\exp \left[\tan \phi\left(\theta_{\mathrm{C}}-\theta_{0}\right)\right] \cos \theta_{\mathrm{C}}\right\}
$$

whereas for any reinforcement below the crack tip $L_{\mathrm{c}(i)}=0$.

$L_{\mathrm{e}(i)} / H$ is determined from the following expression (extension of the formulation of Michalowski (1997) to account for cohesion and wall facing)

$$
\frac{K_{\mathrm{t}}}{\gamma H}=f\left(\theta_{0}, \theta_{\mathrm{h}}, \theta_{\mathrm{C}}, \beta, r_{\mathrm{u}}, \phi, c / \gamma H, \delta, D, w_{\mathrm{b}} / H, \delta_{\text {base }}, L / H, f_{\mathrm{b}}, N\right)
$$

$$
\begin{aligned}
& \frac{K_{\mathrm{t}}}{\gamma H}= \frac{\left(r_{0} / H\right)^{2}\left(f_{1}-f_{2}-f_{3}-f_{4}+f_{5}+f_{6}+r_{\mathrm{u}} f_{\mathrm{w}}\right)-\left(r_{0} / H\right)(c / \gamma H)\left(g_{\mathrm{s}}\right)}{1 / N \sum_{\text {rupture }}\left[\sin \theta_{0}+\left(z_{(i)} / r_{0}\right)\right]} \\
&+\frac{\left(P_{\mathrm{f}} / \gamma H^{2}\right) f_{7}-2 f_{\mathrm{b}} \tan \phi\left(1-r_{\mathrm{u}}\right) \sum_{\text {pullout }}\left\{\left(z_{(i)}^{*} / H\right)\left(L_{\mathrm{e}(i)} / H\right)\left[\sin \theta_{0}+\left(z_{(i)} / r_{0}\right)\right]\right\}}{\frac{1}{N} \sum_{\text {rupture }}\left[\sin \theta_{0}+\left(z_{(i)} / r_{0}\right)\right]}
\end{aligned}
$$

where $z_{(i)}^{*}$ is the overburden depth or reinforcement layer $i$, which for gentle slopes can be less than the depth $z_{(i)}$ (Jewell, 1990), not the case of the walls evaluated herein. $f_{\mathrm{b}}$ is the bond coefficient between soil and reinforcement, and $N$ is the number of geosynthetic layers. $\sum_{\text {rupture }}$ refers to the summation of layers failing in tensile rupture, whereas $\sum_{\text {pullout }}$ refers to the summation of layers failing by pullout.

In equation (21), the adhesion between soil and reinforcement is neglected. Thus, only the interface friction, in the form of the parameter $f_{\mathrm{b}}$, was considered for the calculation of the pullout force.

To find the minimum required reinforcement length, Michalowski (1997) assumed that the most adverse combined failure mechanism makes a required reinforcement value no larger than the one calculated in equation (17), in which all the layers fail in tension. In this way, according to Michalowski (1997), the reinforcement would be used economically (being fully utilised). This is achieved by substituting the value $K_{\mathrm{t}} / \gamma H$ calculated in equation (17) into equation (21). The study by Michalowski (1997) focused only on cohesionless soils. However, for cohesive soils with low friction angles this approach results in excessively long and impractical reinforcement lengths. For this reason, in the present study, the approach previously adopted by Chehade et al. $(2019,2020)$ is employed: the case of a predefined reinforcement length with a combined mode of failure (pullout and tensile failure). The approach used herein may lead to larger values for the required reinforcement strength. However, it allows the designer to evaluate whether, by shortening the reinforcement, the cost savings for the structure would be sufficient to offset the increase of the required strength. Note that reinforcement length affects the costs of a reinforced soil structure more than reinforcement strength, since it is directly related to the volume of reinforced fill material. where

$$
\begin{aligned}
& C_{1}=\sum_{\text {pullout }}\left[\frac{z_{(i)}^{*}}{H}\left(\sin \theta_{0}+\frac{z_{(i)}}{r_{0}}\right)\right] \\
& C_{2}=\sum_{\text {pullout }}\left[\frac{z_{(i)}^{*}}{H}\left(\frac{L_{\mathrm{a}(i)}}{H}-\frac{L_{\mathrm{c}(i)}}{H}\right)\left(\sin \theta_{0}+\frac{z_{(i)}}{r_{0}}\right)\right]
\end{aligned}
$$

It is worth mentioning that the required reinforcement in equation (22) is not a strict lower bound because the pullout force calculation is only an approximation, since it is necessary to assume a distribution of normal stresses (overburden stresses) acting on the reinforcement. However, as stated by Michalowski (1997), it gives a reasonable estimate. Also, from equation (22) it follows that now the required reinforcement is dependent on the number of reinforcement layers $(N)$ chosen.

\section{Modes of failure}

A rotational failure mechanism consisting of a log-spiral passing through the wall toe is assumed and a search for the most critical failure surface (lower bound on the required reinforcement) is performed over $\theta_{0}, \theta_{\mathrm{h}}$ and $\theta_{\mathrm{c}}$. Several cracks may develop over time in a geo-reinforced wall wherever the soil's tensile strength is exceeded. Among these cracks the failure mechanism will always engage the one crack that has the most adverse effect on stability. Maximisation of the function in equation (21) with respect to $\theta_{0}, \theta_{\mathrm{h}}$ and $\theta_{\mathrm{c}}$ implies that the most adverse failure mechanism for the wall is found together with the crack most adverse to the stability of the structure. Note that it is unlikely that the most adverse crack will ever be present, but instead various less critical cracks will form in the reinforced soil over time. However, assuming the existence of the most adverse crack implies that the very worst-case scenario in terms of tensile cracks is assumed, which is a desirable choice for a conservative design. 
For a predefined reinforcement length $L / H$ five failure modes are considered, as shown in Fig. 5. For a given $L / H$ and a potential failure surface (a given set of $\theta_{0}, \theta_{\mathrm{h}}$ and $\theta_{\mathrm{c}}$ ) it is possible to calculate the number of reinforcement layers that have been bypassed and the number that have been crossed by calculating the anchorage length $L_{\mathrm{e}} / H$ (substitution of equations (19) and (20) in equation (18)). If $L_{\mathrm{e}(i)} / H<0$ the evaluated failure surface bypasses the considered layer.

Here a novel solution scheme was implemented to find the type of failure (pullout or tensile rupture) for each crossed layer - that is, for each layer intersected by the potential failure surface analysed. All possible combinations of failure are considered for the set of crossed layers (total of $2^{n_{\text {crossed }}}$ ) and for each combination (some of the crossed layers assumed to fail in tensile rupture and the rest in pullout) the required reinforcement strength $K_{\mathrm{t}} / \gamma H$ is calculated with equation (22). Then, the initial assumption of failure for each layer is checked following the steps shown in Fig. 5 and by comparing the pullout force $\left(T_{\mathrm{p}}\right)$ with the reinforcement strength $(T)$ in each layer

$$
\begin{aligned}
\frac{T_{\mathrm{p}(i)}}{\gamma H^{2}} & =2 \frac{L_{\mathrm{e}(i)}}{H} \frac{z_{(i)}^{*}}{H} f_{\mathrm{b}} \tan \phi\left(1-r_{\mathrm{u}}\right) \\
\frac{T_{(i)}}{\gamma H^{2}} & =\frac{K_{\mathrm{t}}}{N \gamma H}
\end{aligned}
$$

If for a given potential failure surface no possible combination with at least one layer failing in tension is

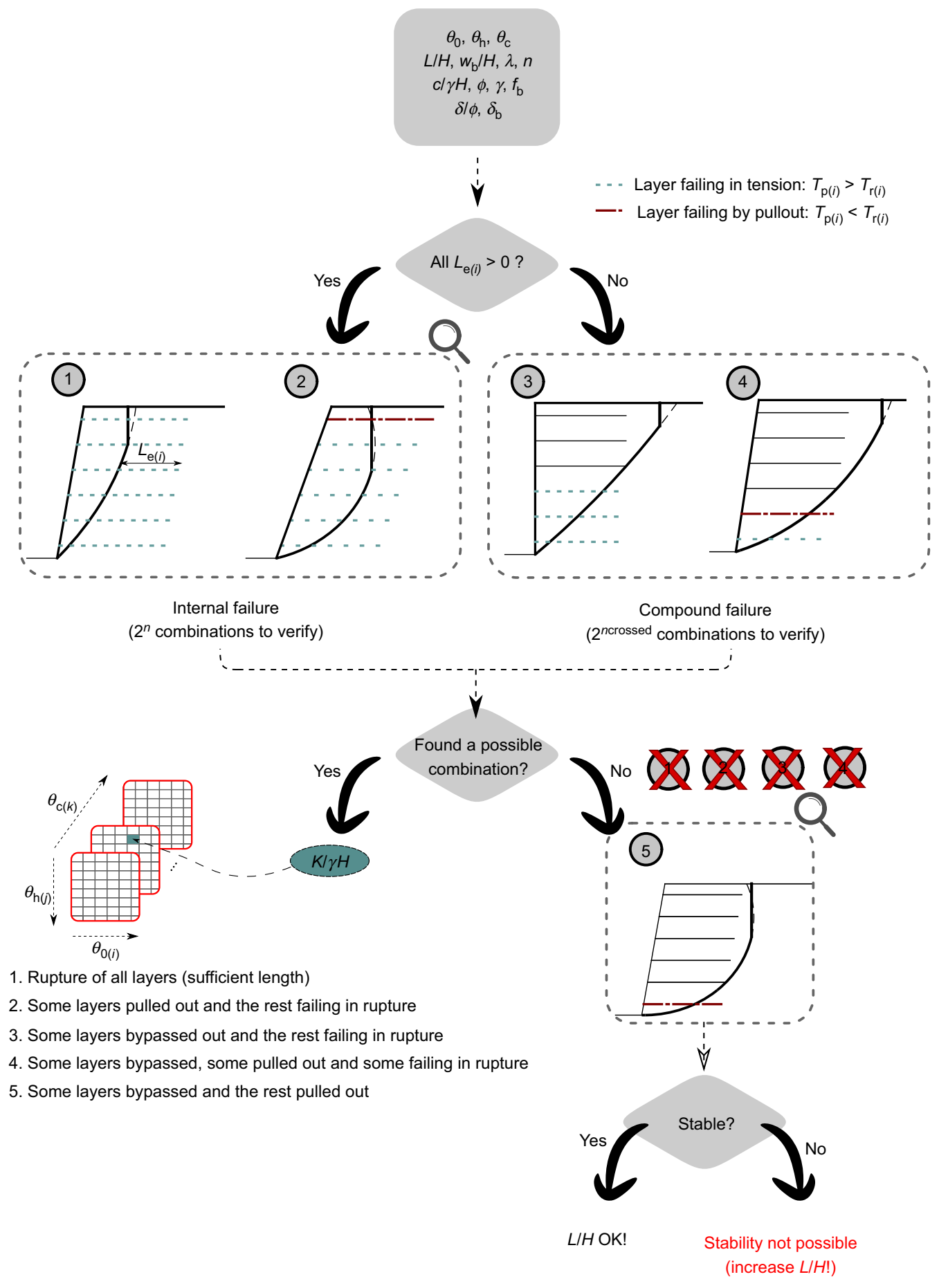

Fig. 5. Failure modes considered 
feasible, a final verification is carried out, corresponding to mode 5 in Fig. 5. In this verification, it is checked whether the pullout of all the crossed layers, together with the contributions of soil cohesion and of the facing is sufficient to guarantee stability of the system. In this case, equation (22) reduces to the following expression, from which the minimum length of reinforcement required to guarantee stability can be calculated

$$
\begin{aligned}
2 f_{\mathrm{b}} \tan \phi\left(1-r_{\mathrm{u}}\right)\left(\frac{C_{1} L}{H}-C_{2}\right) \\
\geq\left(\frac{r_{0}}{H}\right)^{2}\left(f_{1}-f_{2}-f_{3}-f_{4}+f_{5}+f_{6}+r_{\mathrm{u}} f_{\mathrm{w}}\right) \\
\quad+\left(\frac{r_{0}}{H}\right)\left(\frac{c}{\gamma H}\right)\left(g_{\mathrm{s}}\right)-\frac{P_{\mathrm{f}}}{\gamma H^{2}} f_{7}
\end{aligned}
$$

If the predefined length used is smaller than the minimum required, the given length is too short for the case evaluated. Note that mode 5 does not result in any required reinforcement strength $K_{\mathrm{t}} / \gamma H$ since no layer fails in tensile rupture to contribute to internal energy dissipation (equation (27)). However, it allows checking whether the predefined length $L / H$ is sufficient to guarantee stability for any potential failure surface.

\section{Failure mechanisms emerging at the wall facing}

Note that, due to tension cracks, potential failure mechanisms passing above the toe are no longer self-similar (Utili, 2013) and therefore could in principle be critical. In all the cases analysed here, the critical failure mechanism turned out to be the one passing at the toe.

The values for inter-block friction may vary significantly because there is a range of block types commercially available (solid, with cores, with shear keys, etc.; see Berg et al. (2009) for examples) with different connection systems (Holtz \& Lee, 2002). BSI (2019) gives, for guidance, a minimum value of 0.4 for the coefficient of static friction at solid concrete-concrete interfaces, which is around $22^{\circ}$. Values in the range of $30-40^{\circ}$ have been previously used in analytical and numerical analysis of reinforced soil walls (Wu \& Payeur, 2015; Leshchinsky et al., 2017). Hatami \& Bathurst (2005) determined a value as large as $57^{\circ}$ in laboratory shear tests for solid masonry concrete blocks with shear keys. Bathurst et al. (2008) provide a set of results for interface shear behaviour of typical modular block units with varied interface shear transfer mechanisms and vertical loading arrangements. They found values ranging from $25^{\circ}$ to $35^{\circ}$ at $2 \%$ of block displacement and from around $30^{\circ}$ to $40^{\circ}$ in peak shear.

In cases where the geosynthetic connection to the wall face is achieved by friction (reinforcement placed between blocks), the reinforcement could also influence the blockblock interface properties (Leshchinsky et al., 1995). Therefore, design values should be obtained from laboratory test results for the specific combination of facing blocks and geosynthetics to be used, for which standard methods can be found in ASTM (2018b) and ASTM (2018a).

In this paper failure mechanisms emerging above the wall toe were considered for both UD and LID reinforcement distributions by discretising the wall facing for each blockblock interface and calculating the minimum amount of required reinforcement associated with each mechanism. The equations are provided in Appendix 3. Only reinforcement layers located above the failure mechanism exit point at the wall face were considered in the calculations $\left(N^{\prime}\right.$ in equation (51) of Appendix 3).
For the results presented in the section 'Results and discussion', the number of blocks was assumed as twice the number of reinforcement layers, $N_{\mathrm{b}}=12$, with a block unit weight of $21.8 \mathrm{kN} / \mathrm{m}$ and a block-block interface friction angle, $\delta_{\mathrm{bb}}$, of $38^{\circ}$. The critical failure mechanism remained passing through the wall toe for all the cases considered with $L / H=0.7$ and $w_{\mathrm{b}} / H>0.05$, even with the presence of tension cracks, low soil friction angle and cohesion $\left(\phi=15^{\circ}\right.$ and $c / \gamma H=0.05)$, thin block facing width $\left(w_{\mathrm{b}} / H=0.05\right)$, vertical facing batter $\left(\beta=90^{\circ}\right)$ and LID reinforcement distribution. An investigation of the effect of reducing the value of $\delta_{\mathrm{bb}}$ was then performed and it was verified that instability in the region of the top blocks (above the top reinforcement) would only occur in the case of LID distribution for block-block friction angles below $17^{\circ}$, therefore it can be concluded that the mechanism is not critical.

A case where mechanisms daylighting is critical was for UD reinforcement distribution, very thin block width $\left(w_{\mathrm{b}} / H \leq 0.05\right)$ and low soil friction angle and cohesion. In this case, the critical failure mechanism tends to daylight at the interface between the first and second wall blocks, from the wall toe, resulting in an increase in the reinforcement needed or mode 5 type of failure (Fig. 5). This is indicated in the results presented in Fig. 10 in the next section. Increasing reinforcement density (here $N=6$ was used) would prevent this type of failure.

Note that the local stability of modular block facing walls should also be checked for connection failure, shear failure and crest toppling (NCMA, 2010). This last case refers to the local overturning failure of the top blocks in the unreinforced section of the structure, being particularly relevant for reinforcements distributed linearly along the wall height, in which reinforcement vertical spacings in the upper region of the wall are larger. Local facing stability checks are outside the scope of the paper.

\section{RESULTS AND DISCUSSION \\ Method verification}

Few studies have evaluated the influence of facing on the design of reinforced soil walls (Ismeik \& Guler, 1998; Baker \& Klein, 2004; Leshchinsky et al., 2010; Xie et al., 2016) and, to the best of the present authors' knowledge, none has considered the case of cohesive frictional backfills. Therefore, to validate the methodology presented here, the authors decided to consider the example presented by Leshchinsky et al. (2010) for the case of cohesionless soils. Leshchinsky et al. (2010) used a limit equilibrium approach assuming a log-spiral failure mechanism, accounting for the resistance of the facing (toe resistance). The toe resistance was represented by the horizontal force acting at the wall toe $\left(R_{\mathrm{h}}\right.$ in Fig. 4$)$, considered as an external force. The facing element was treated as part of the system and thus no consideration of the location of the resultant lateral forces acting on the wall was required. Sufficient reinforcement length was considered so that all layers would fail in tensile rupture.

Leshchinsky et al. (2010) provided stability charts for prescribed values of $R_{\mathrm{h}} / n T$ that should be used in a trial-and-error process to obtain the required reinforcement strength. Therefore, the facing width is implicitly considered. To obtain comparable results, equation (17) should be re-written as a function of $R_{\mathrm{h}} / n T$. The force acting on the wall, $P_{\mathrm{f}}$, can be expressed as a function of the required reinforcement strength $\left(K_{\mathrm{t}} / \gamma H\right)$

$$
P_{\mathrm{f}}=\frac{R_{\mathrm{h}}}{\cos \delta_{\mathrm{h}}}=\frac{\psi\left(K_{\mathrm{t}} / \gamma H\right) \gamma H^{2}}{\cos \delta_{\mathrm{h}}}
$$

where $\psi=R_{\mathrm{h}} /(n T)$. 
Substitution of equation (28) into equation (17) gives

$$
\begin{aligned}
\frac{K_{\mathrm{t}}}{\gamma H}= & {\left[\frac{\left(f_{1}-f_{2}-f_{3}-f_{4}+f_{5}+f_{6}+r_{\mathrm{u}} f_{\mathrm{w}}\right)}{\left(H / r_{0}\right)\left(g_{\mathrm{r}}\right)}-\left(\frac{c}{\gamma H}\right)\left(\frac{g_{\mathrm{s}}}{g_{\mathrm{r}}}\right)\right] } \\
& \times \frac{1}{\left\{\left[1+\left(H / r_{0}\right)\right] \times\left(\psi / \cos \delta_{\mathrm{h}}\right) \times\left[f_{7} /\left(g_{\mathrm{r}}\right)\right]\right\}}
\end{aligned}
$$

The objective function in equation (29) considers a sufficient length for the reinforcement so all layers fail in tensile rupture. This expression was used to obtain $K_{\mathrm{t}} / \gamma H$ for given values of $\psi$. Results obtained for $\phi=30^{\circ}$ are plotted in Fig. 6 together with the results of Leshchinsky et al. (2010), for comparison. Curves for both UD and LID distributions are shown and, for consistency, the required reinforcement is represented as $2 K_{\mathrm{t}} / \gamma H$ in the authors' calculation. The location of the force acting on the wall was assumed to be at one-third of the wall height $(D=H / 3)$. The chart in Fig. 6 should be used iteratively, by first assuming a $\psi$ value, then reading off the correspondent $K_{\mathrm{t}} / \gamma H$ from the chart and finally verifying $\psi$ by calculation of $R_{\mathrm{h}}$

$$
R_{\mathrm{h}}=R_{\mathrm{v}} \tan \delta_{\text {base }}
$$

where $R_{\mathrm{V}}$ is the normal force acting at the base of the facing (Fig. 4).

Good agreement with the results of Leshchinsky et al. (2010) can be observed, with maximum differences not larger than $13 \%$ for UD distribution. In general, the minimum required reinforcement calculated with the extended formulation presented herein was slightly larger than the values reported by Leshchinsky et al. (2010), and therefore the difference is on the safe side. Nonetheless, smaller values were obtained for LID distribution and a vertical wall $\left(\beta=90^{\circ}\right)$, since in Leshchinsky et al. (2010) UD and LID distributions gave rise to the same results for $R_{\mathrm{h}} / n T>0$ and $\beta=90^{\circ}$.

\section{Design charts}

In the formulation introduced here the influence of seepage could be accounted for by way of the pore pressure coefficient $r_{\mathrm{u}}$ (Bishop \& Morgenstern, 1960); however, for sake of simplicity the results presented here are for the case of drained soil $\left(r_{\mathrm{u}}=0\right)$. The drainage system in reinforced soil walls with cohesive-frictional soils is particularly important

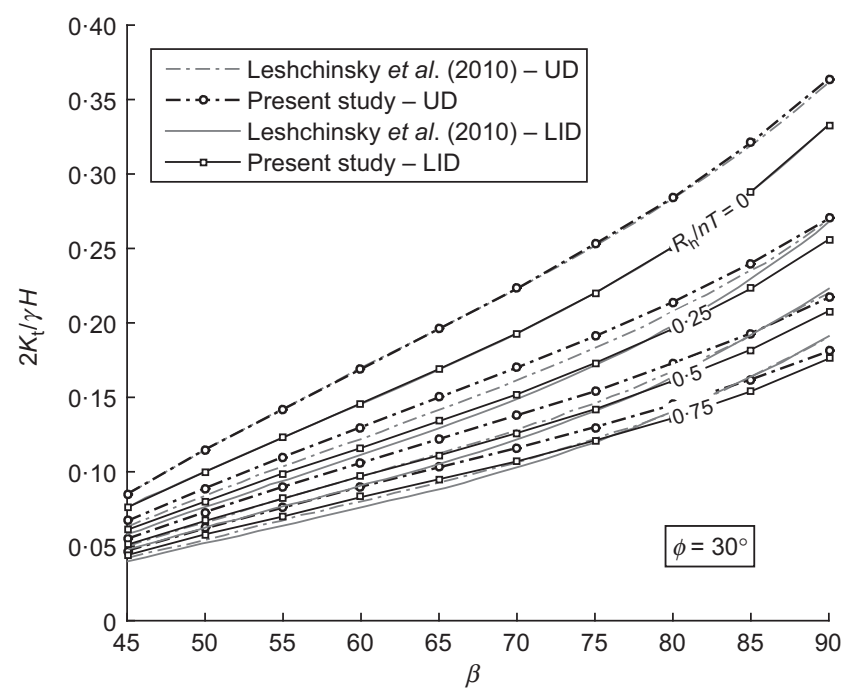

Fig. 6. Comparison of required tensile strength in the present study and in Leshchinsky et al. (2010) $\left(\phi=30^{\circ}, D=H / 3\right.$, modified force direction). $R_{\mathrm{h}}$ is the horizontal force at the wall toe as indicated in Fig. 4 since these materials present medium to low permeability that can cause the build-up of pore-water pressure. Indeed, Koerner \& Koerner (2018) have shown that faulty drainage in cohesive soils was a major cause of the wall failures investigated in their study. These arguments underline the critical importance of designing a suitable drainage system to keep the pore pressure within the prescribed values. Recommendations on drainage systems can be found in Koerner (2005) and Koerner \& Koerner (2011), and in design guidelines such as Berg et al. (2009), NCMA (2010) and BSI (2010).

A parametric analysis was conducted to investigate the effect of the following parameters

(a) normalised soil cohesion, $c / \gamma H: 0 \cdot 05$ and $0 \cdot 1$

(b) soil friction angle, $\phi$ : from $15^{\circ}$ to $35^{\circ}$

(c) facing batter, $\beta: 70^{\circ}, 80^{\circ}$ and $90^{\circ}$

(d) block width (toe to heel), $w_{\mathrm{b}} / H$ : 0, 0.05, 0.1, 0.15 and $0 \cdot 25$

(e) location of the reaction force acting on the wall, $D: H / 2$, $H / 3$ and $H / 4$

(f) facing-backfill interface friction angle, $\delta / \phi: 0,1 / 3$ and $2 / 3$

(g) facing-foundation interface friction angle, $\delta_{\mathrm{b}} / \phi: 0,1 / 3$ and $2 / 3$

(h) reinforcement length, $L / H: 0 \cdot 6,0 \cdot 7$ and sufficiently long.

The authors selected the values for $L / H$ based on recommendations of design standards for the minimum reinforcement length from Berg et al. (2009), NCMA (2010), BSI (2010) and Aashto (2017). It is common practice to adopt a minimum reinforcement length for reinforced soil structures around $70 \%$ of the structure's height. Design standards such as Aashto, FHWA and BSI recommend $L \geq$ $0.7 \mathrm{H}$ with a minimum absolute length of not less than $2.5 \mathrm{~m}$ for Aashto (2017) and FHWA (Elias \& Christopher, 2001) and $3 \mathrm{~m}$ for BSI (2010). A minimum value of $0 \cdot 6 \mathrm{H}$ of not less than $1.2 \mathrm{~m}$ is recommended by the private sector standard NCMA (2010) and by BSI for walls subjected to low thrust (but still with an absolute length of not less than $3 \mathrm{~m}$ ).

The soil and facing block unit weights were set to $20 \mathrm{kN} / \mathrm{m}^{3}$ and $21.8 \mathrm{kN} / \mathrm{m}^{3}$, respectively. The number of layers $N=6$, the bond coefficient between the soil and reinforcement $f_{\mathrm{b}}=0 \cdot 5$, and the block-block interface friction $\delta_{\mathrm{bb}}=38^{\circ}$ were kept the same in all analyses.

The results presented here are for the modified direction of the force acting on the wall, representative of a wall composed of stacked block units (Fig. 4(b)). Charts for the conventional direction can be easily produced using $\delta_{\mathrm{h}}=$ $\delta+\beta-\pi / 2$ in equation (16) and the substitution of $f_{7}$ related to the conventional direction given in Appendix 2 in the objective function to be optimised (equation (17), when a sufficient reinforcement length is assumed, or equation (22), when a fixed length is given). In all analyses, for the calculation of the frictional capacity at the wall toe, both the wall weight and the vertical component of the interface friction between the reinforced soil and the wall facing were considered (equation (12)).

For cohesive-frictional soils, the authors verified that mode 1 (rupture of all layers) and mode 4 (some layers bypassed, some pulled out and the rest failing in rupture) in Fig. 5 were the more common modes of failure for the reinforcement lengths considered $(L / H=0.6$ and $L / H=0 \cdot 7)$. Mode 3 (some layers bypassed and the rest failing in rupture) was not the critical mode of failure in any of the analyses with UD distribution carried out with $L / H=0 \cdot 7$. For $L / H=0.6$ it was the critical mode in a few situations, mostly for large $w_{\mathrm{b}} / H$ and low $\phi$ values. For LID distribution mode 3 was 
critical for cases with $L / H=0.7$ only with the lowest friction angle investigated $\left(\phi=15^{\circ}\right)$, whereas for $L / H=0.6$ more cases were detected.

Mode 5 (insufficient length) was critical and mostly not satisfied for the shorter length of $L / H=0.6$ with UD distribution, and only for the lowest friction angle evaluated $\phi=15^{\circ}$ and $c / \gamma H=0.05$, which means that the given length

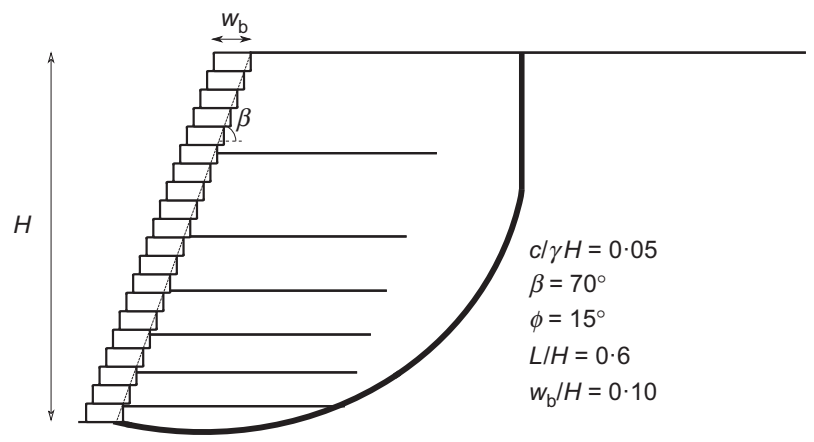

Fig. 7. Case of unstable reinforced soil structure: predefined reinforcement length too short $(D=H / 3$, modified force direction, LID distribution)

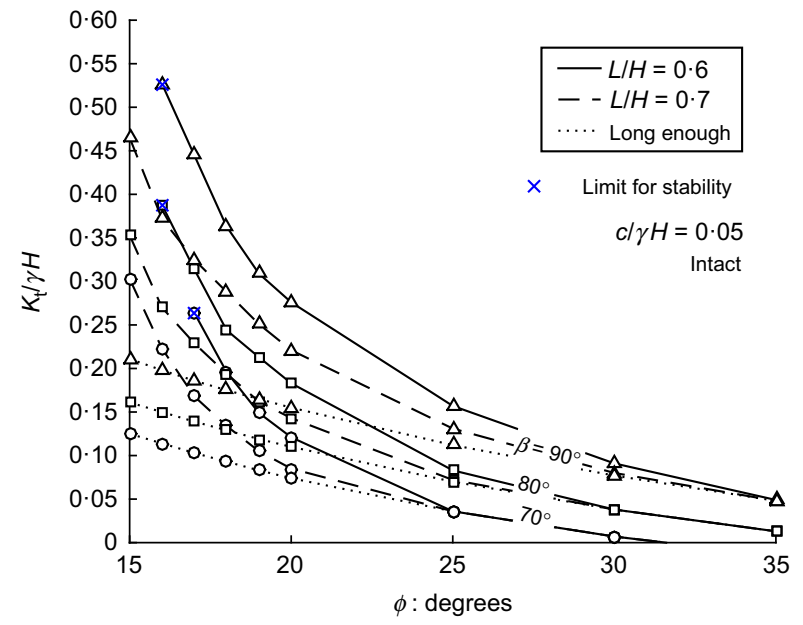

(a)

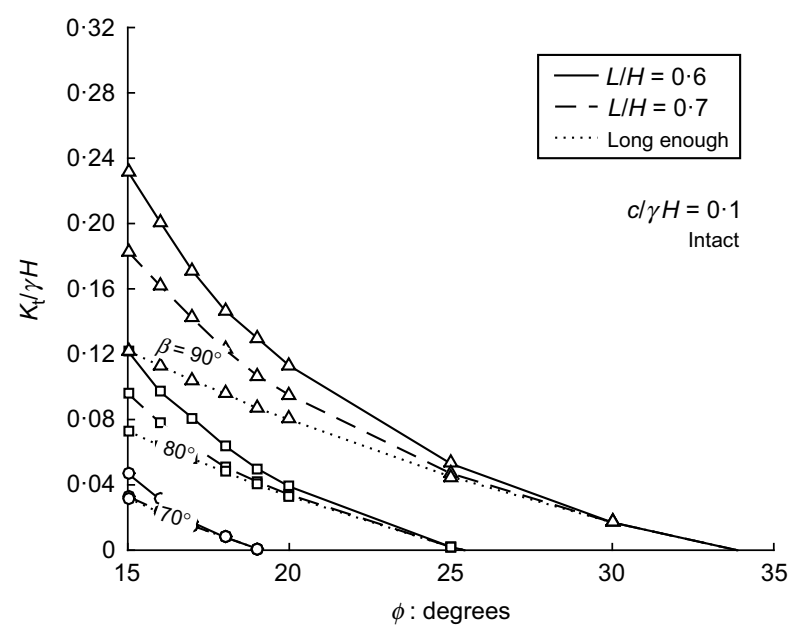

(c) was too short. Fewer cases were found not stable for LID distribution such as $c / \gamma H=0.05, \phi=15^{\circ}, L / H=0.6, \beta=$ $70^{\circ}$ and $w_{\mathrm{b}} / H \leq 0 \cdot 1$, as shown in Fig. 7. In these cases the failure surface crosses only the first reinforcement layer, closer to the wall toe.

Michalowski (1997) found that for the case of noncohesive reinforced soil slopes with significant pore-water pressure the critical failure surface had the centre of rotation below the wall crest $\left(\theta_{0}<0\right)$ and sometimes below the top reinforcement layer. When that is the case, the reinforcement layers above the failure surface centre of rotation $\left(\sin \theta_{0}+z_{i} / r_{0}<0\right)$ are subjected to compression and therefore likely to kink or buckle. Hence, no energy is dissipated in those layers and the expression in equation (6), after integration of the increment of the dissipation rate between 0 and $\theta_{\mathrm{h}}$ becomes

$$
\dot{D}_{\mathrm{r}(\mathrm{B}-\mathrm{D})}==\frac{1}{2} K_{\mathrm{t}} \dot{\theta} r_{0}^{2}\left\{\exp \left[2 \tan \phi\left(\theta_{\mathrm{h}}-\theta_{0}\right)\right] \sin ^{2} \theta_{\mathrm{h}}\right\}
$$

In this study, it was found that compression of the top layers occurs in some particular cases and mostly for UD distribution. Fig. 8 shows, for three wall facing batters and UD distribution, the required reinforcement strength obtained for the prescribed reinforcement lengths of $0.6 \mathrm{H}$

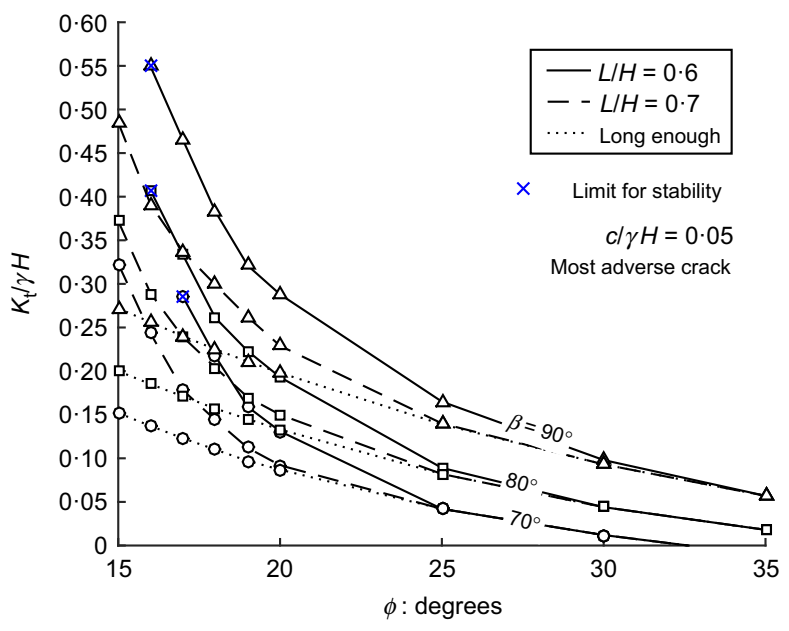

(b)

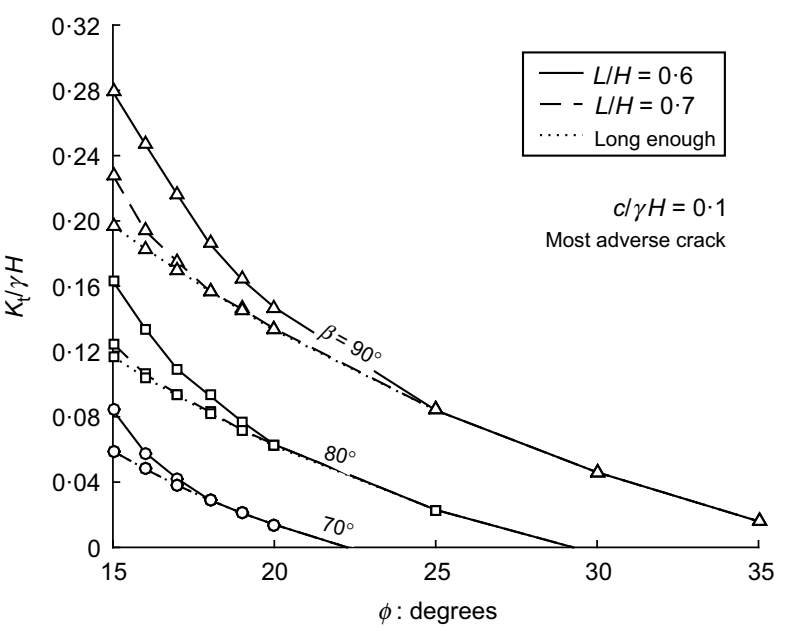

(d)

Fig. 8. Required reinforcement versus soil friction angle $\phi$ for three values of wall facing batter, $\beta$, and for different $L / H$ (sufficient length for rupture of all layers, $0.6 H$ and $0.7 H)\left(w_{\mathrm{b}} / H=0.1, \delta=2 / 3 \phi, \delta_{\text {base }}=15^{\circ}, \delta_{\mathrm{bb}}=38^{\circ}, D=H / 3\right.$, modified force direction, UD reinforcement distribution). (a) and (b) are for a reinforced soil wall in intact soil and in the presence of tension cracks for $c / \gamma H=0.05$, respectively; while (c) and (d) are for $c / \gamma H=0 \cdot 1$. The most adverse crack to stability is considered. The ' $x$ ' markers indicate the limit for stability, beyond which the prescribed reinforcement length is not sufficient to provide stability 
and $0.7 \mathrm{H}$. A set of curves calculated from equation (17) is also presented, having assumed that all layers fail in tensile rupture. The ' $x$ ' markers on the charts indicate the points beyond which mode 5 in Fig. 5 becomes critical, indicating the need to increase the prescribed reinforcement length.

The curves in Fig. 8 tend to converge as the soil angle of shearing resistance $\phi$ and the normalised cohesion $c / \gamma H$ increase. This means that for these cases and the given reinforcement length the analyses considering the possibility of combined failure lead to the same required reinforcement as the analyses that account only for the tensile rupture of all layers, the approach adopted by Michalowski (1997).

By decreasing $\phi$, the curves increasingly diverge, to such a point that the required reinforcement can be more than twice the value obtained for a sufficiently long reinforcement (Fig. 9). This difference is more prominent for lower normalised cohesion values (see curves for $c / \gamma H=0.05$ ). The final choice then should consider the relative impact on the structure's cost of increasing the reinforcement length as opposed to the reinforcement strength. Note that a longer reinforcement requires a larger volume of backfill, which will also have an impact on the structure's final cost. Similar results for LID distribution can be found in Appendix 4, for which the required reinforcement is always less than the values obtained for UD distribution, as is to be expected (Michalowski, 1997; Abd \& Utili, 2017).

The presence of tension cracks is more detrimental to stability, especially for lower soil friction angles, larger cohesion and facing batter, as can be seen from the comparison of Fig. 8(a) with Fig. 8(b) and comparison of Fig. 8(c) with Fig. 8(d), for a sufficiently long reinforcement. By adopting a predefined reinforcement length of $0.6 \mathrm{H}$ and $0.7 \mathrm{H}$, the influence of cracks becomes less pronounced (especially for $c / \gamma H=0 \cdot 05$ ).
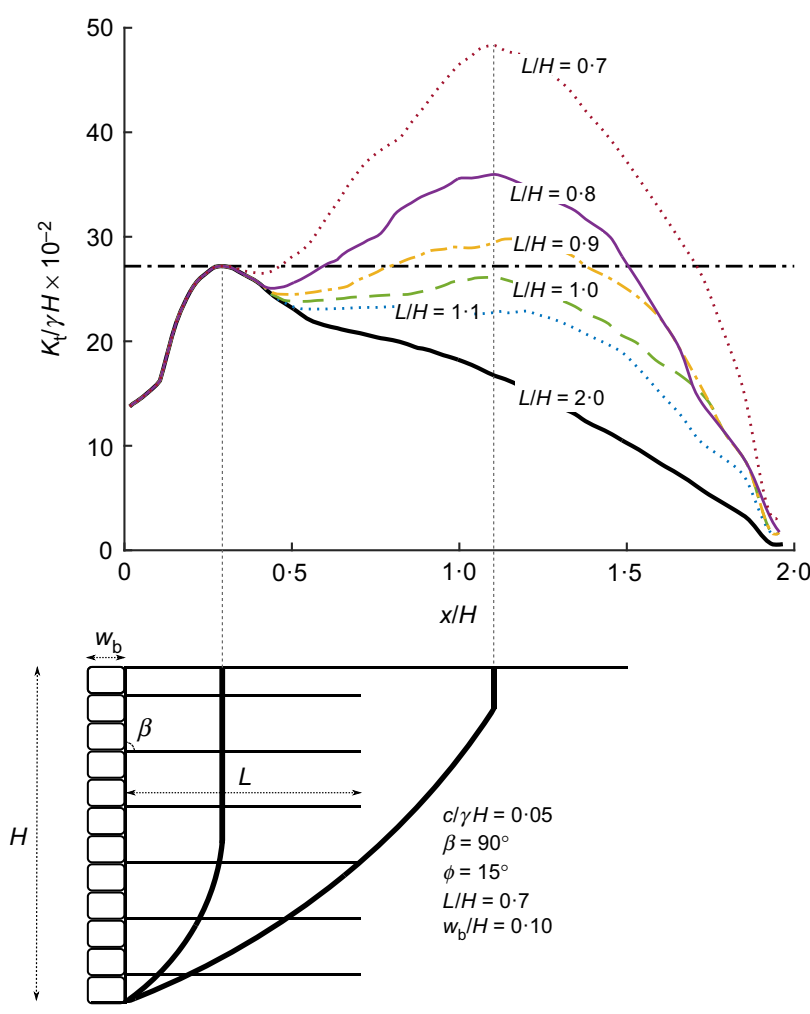

Fig. 9. Comparison of required reinforcement strength for different values of $L / H$ for a reinforced soil wall in the presence of tension cracks. The most adverse crack to stability is considered. $\left(\beta=90^{\circ}\right.$, $w_{\mathrm{b}} / H=0 \cdot 1, \delta=2 / 3 \phi, \delta_{\text {base }}=15^{\circ}, \delta_{\mathrm{bb}}=38^{\circ}, D=H / 3, c / \gamma H=$ $0.05, \phi=15^{\circ}$, modified force direction, UD reinforcement distribution)
Since $0.7 H$ is a common reinforcement length used in design, the next charts were produced for this value. Note, however, that in case of a different length the required reinforcement strength may change, as can be seen in Fig. 9 for a vertical wall. For the next set of results, when not stated otherwise, the normalised block width $w_{\mathrm{b}}=H$ is set as $0 \cdot 1$, the facing-reinforced fill interface friction $\delta$ as $2 / 3 \phi$, the facingfoundation interface friction $\delta_{\text {base }}$ as $15^{\circ}$, and the location of the force acting at the wall at $1 / 3$ of the wall height $(D=H / 3)$.

The best lower bounds to the required reinforcement strength $\left(K_{\mathrm{t}} / \gamma H\right)$ for $L / H=0.7$ were obtained by the maximisation of the function in equation (21) and are shown in Fig. 10 plotted against the normalised facing block width $w_{\mathrm{b}} / H$. Commercial block units for reinforced soil walls are available in a range of dimensions that depend on the country. According to Berg et al. (2009) the nominal front to back width for dry-stacked block facing typically ranges from 20 to $60 \mathrm{~cm}$ in the USA. In practice, this gives maximum values of $w_{\mathrm{b}} / H$ of around $0 \cdot 1$. Indeed, typical normalised block widths from 0.03 to $0 \cdot 1$ have been reported in the literature for retaining walls (Fishman et al., 1993; Bathurst et al., 1993b; Farrag et al., 2004; Riccio et al., 2014; Allen \& Bathurst, 2014a, 2014b; Salem et al., 2018). Therefore, values of $w_{\mathrm{b}} / H$ up to $0 \cdot 1$ are considered to be representative of practical field values. Nevertheless, results for $w_{\mathrm{b}} / H$ up to $0 \cdot 25$ are presented in the charts in Fig. 10 in order to evaluate the effect of a very thick facing, with the wall tending towards a gravitational structure.

From Fig. 10 it can be observed that the facing element may provide a relevant contribution to the structure's stability, reducing the minimum required reinforcement by considerable amounts for low soil friction angles. With wall thickness increasing, the mobilisation of reinforcement loads decreases, with a smaller proportion of the soil load transferred to the reinforcement. In fact, a larger block width implies a larger facing weight and frictional resistance at the wall/block base, which makes the facing element carry more load. However, it is worth mentioning that the designer should be careful in accounting for this contribution because it may not always be possible to guarantee the presence of the toe resistance throughout the entire lifespan of the structure. As in the previous charts, the impact of tension cracks is more significant for higher cohesion values (Figs 10(c) and 10(d)).

In Fig. 11 the contribution of the horizontal toe resistance $\left(P_{\mathrm{f}, \mathrm{h}}\right)$ relative to the soil horizontal thrust $\left(P_{\mathrm{f}, \mathrm{h}}+n T\right)$ is illustrated for $w_{\mathrm{b}} / H=0 \cdot 1$. Results for UD (Figs 11 (a) and 11 (b)) and LID (Figs 11(c) and 11(d)) reinforcement distributions are plotted, for $c / \gamma H=0.05$ and $c / \gamma H=0.1$. The lowest contributions of the facing, between $5 \%$ and $10 \%$ for UD distribution, and in the range between $10 \%$ and $20 \%$ for LID, are associated with the weaker soil $\left(\phi=15^{\circ}\right.$ and $c / \gamma H=0.05)$, for which the load capacity of the wall is not sufficient to sustain the retained fill. In these cases, the structure's stability is mostly relying on the reinforcement. With the shear strength parameters of the soil $(\phi$ and $c / \gamma H)$ increasing, the total thrust to be balanced diminishes, and thus the load capacity of the facing becomes more significant in relative terms. For $\phi=25^{\circ}$ and $c / \gamma H=0.05$, for example, the facing carries around $20 \%$ of the load for a vertical wall and up to $50 \%$ for a wall batter of $70^{\circ}$. For a larger cohesion, $c / \gamma H=0 \cdot 1$, the relative contribution increases even further, with the influences of both the wall batter and the presence of cracks becoming more prominent: for vertical walls, the facing contribution is around $25-43 \%$, whereas for $\beta=70^{\circ}$ it reaches $100 \%$ regardless of reinforcement distribution and of the presence of cracks.

The effects of facing-backfill interface friction and foundation-block interface friction are investigated in Fig. 12, with Figs 12(a) and 12(b) referring to $c / \gamma H=0.05$ 


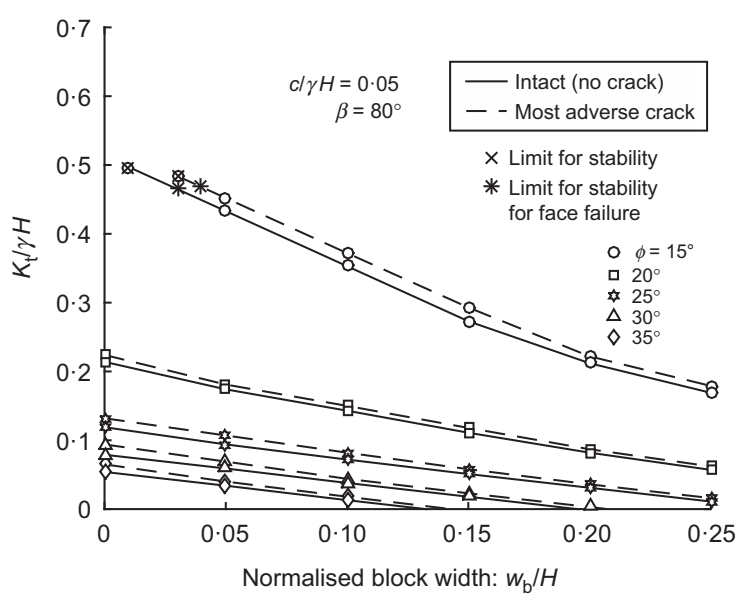

(a)

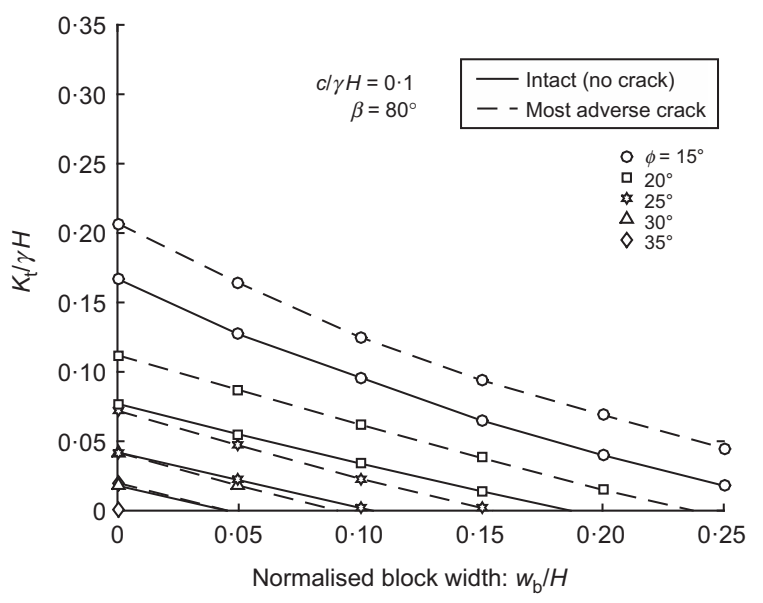

(c)

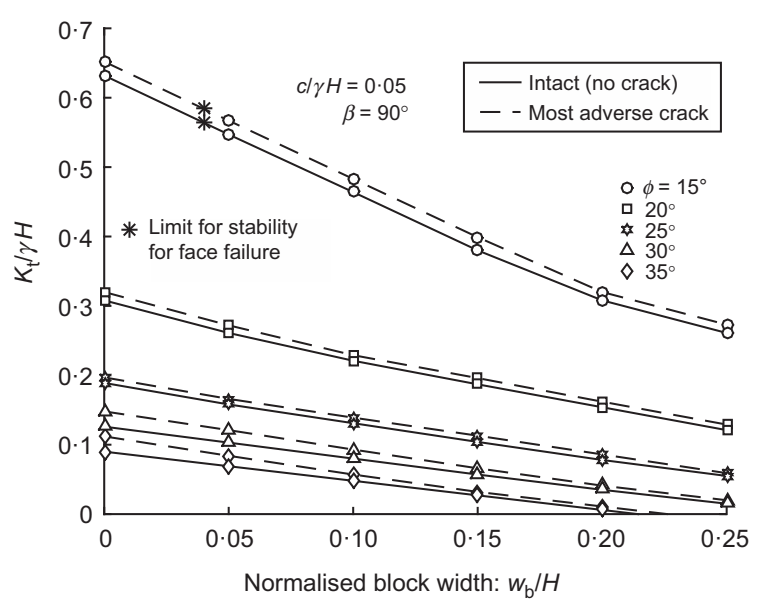

(b)

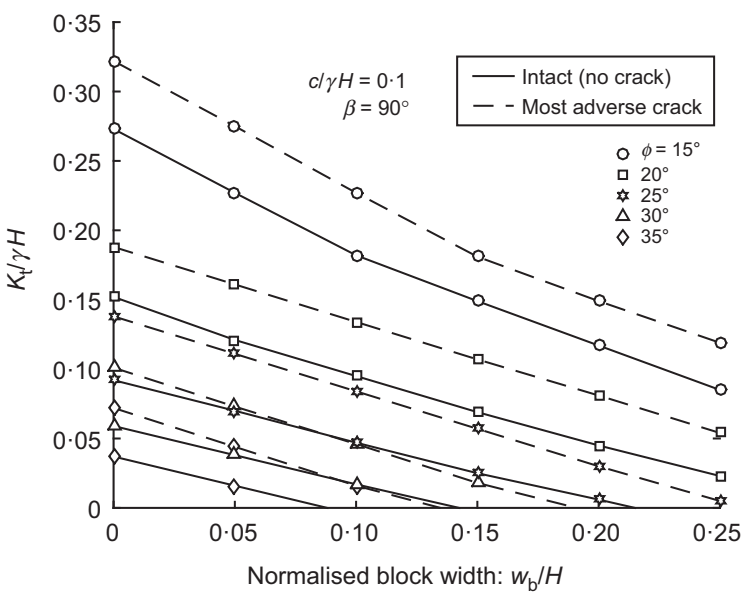

(d)

Fig. 10. Required reinforcement plotted against $w_{\mathrm{b}} / H$ for a reinforced soil wall in intact soil and in the presence of tension cracks. The most adverse crack to stability is considered. (a) and (b) are for $c / \gamma H=0.05$ with $\beta=80^{\circ}$ and $\beta=90^{\circ}$, respectively; while (c) and (d) are for $c / \gamma H=0.1$ with $\beta=80^{\circ}$ and $\beta=90^{\circ}$, respectively. $\left(\delta=2 / 3 \phi, \delta_{\text {base }}=15^{\circ}, \delta_{\mathrm{bb}}=38^{\circ}, L / H=0 \cdot 7, D=H / 3\right.$, modified force direction, UD reinforcement distribution). The ' $x$ ' and ' $*$ ' markers indicate the limit for stability, for toe failure and failure surface emerging at the face, respectively, beyond which the prescribed reinforcement length is not sufficient to provide stability

and Figs $12(\mathrm{c})$ and $12(\mathrm{~d})$ to $c / \gamma H=0 \cdot 1$. Two facing batters were considered: $\beta=80^{\circ}$ (Figs $12(\mathrm{a})$ and $12(\mathrm{c})$ ) and $\beta=90^{\circ}$ (Figs 12(b) and 12(d)). For $c / \gamma H=0.05$ the minimum required reinforcement, $K_{\mathrm{t}} / \gamma H$, required in the presence of tension cracks ranges from 1 to 1.2 times the amount needed for intact soil, whereas for $c / \gamma H=0 \cdot 1$ it ranges from $1 \cdot 2$ to $3 \cdot 2$ times. Similar results were found for LID distribution and are shown in Appendix 4 (see Fig. 17).

From Fig. 12 it can be seen that the combined effect of facing-backfill interface friction and block-toe friction results in the most appreciable decrease in reinforcement amount. This stems from the vertical component of downdrag acting at the facing-backfill interface, which results in an increased reaction/friction at the toe. For $\phi=20^{\circ}$, for example, going from $\delta / \phi=\delta_{\mathrm{b}} / \phi=2 / 3$ to $\delta / \phi=\delta_{\mathrm{b}} / \phi=0$ increases the amount of reinforcement required by $1 \cdot 3$ times for $c / \gamma H=0.05$ and by $1.9\left(\beta=80^{\circ}\right)$ and 1.5 times $\left(\beta=90^{\circ}\right)$ for $c / \gamma H=0 \cdot 1$. By increasing the soil friction angle to $\phi=$ $30^{\circ}$ the reduction in the required reinforcement is even more pronounced: for $c / \gamma H=0.05$, by reducing $\delta / \phi$ and $\delta_{\mathrm{b}} / \phi$ from $2 / 3$ to 0 the increase in the amount of reinforcement required is about 3.6 times for $\beta=80^{\circ}$ and about $2 \cdot 1$ times for $\beta=90^{\circ}$, while for $c / \gamma H=0.1$ one goes from a situation where no reinforcement is needed to another where reinforcement is required.

For the previous analyses, the location of the force carried by the wall facing at one-third of the wall height was assumed
( $D=H / 3$ ). To investigate the sensitivity of the results to this assumption, other points of applications for the force were considered: at the mid-height of the wall $(D=H / 2)$, at one-third of the wall height $(D=H / 3)$ and at a quarter of the wall height $(D=H / 4)$. Results for UD distribution are plotted in Fig. 13, while the results for LID distribution are shown later in Fig. 18 in Appendix 4.

From Fig. 13 it emerges that the influence of the location, $D$, of the force stemming from the wall is significant only for large values of normalised cohesion $(c / \gamma H=0 \cdot 1)$ and in the presence of tension cracks. For instance, for $\beta=90^{\circ}, c / \gamma H=0.1$ and in the presence of tension cracks, for $\phi=15^{\circ}$, the facing carries around $12 \%$ of the load regardless of $D$, whereas for $\phi=35^{\circ}$ the facing contribution is around $70 \%$ for $D=H / 4$ and $D=H / 3$ and around $50 \%$ for $D=H / 2$. In contrast, for $c / \gamma H=0.05$ and in the presence of tension cracks $D$ makes very little difference. The influence of $D$ is less pronounced for LID distribution: for $\beta=90^{\circ}, c / \gamma H=0.1$ and in the presence of tension cracks, around $17 \%$ of the load is carried by the facing when $\phi=15^{\circ}$, regardless of $D$, whereas the facing contribution for $\phi=35^{\circ}$ is around $70 \%$ for $D=H / 4$ or $D=H / 3$ and around $60 \%$ for $D=H / 2$.

\section{CONCLUSIONS}

This study presented a new semi-analytical method based on limit analysis to design the reinforcement strength 


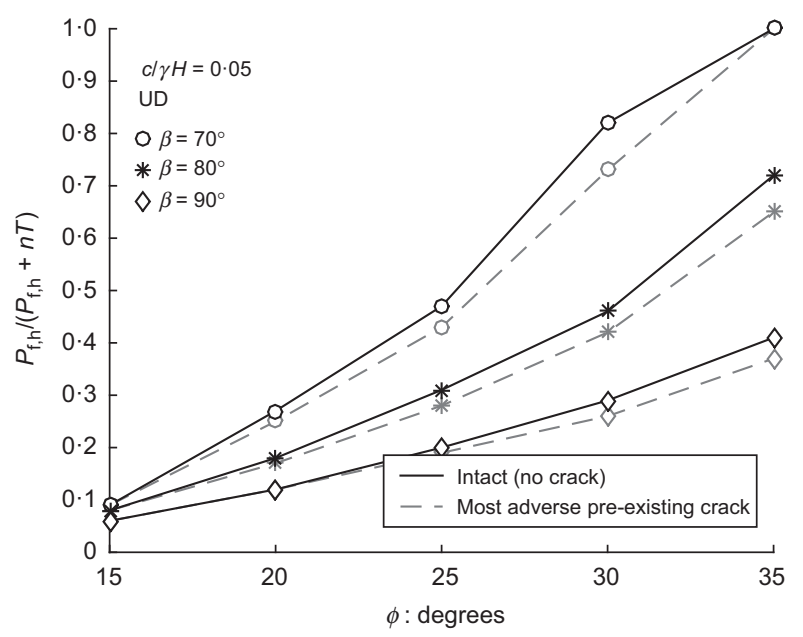

(a)

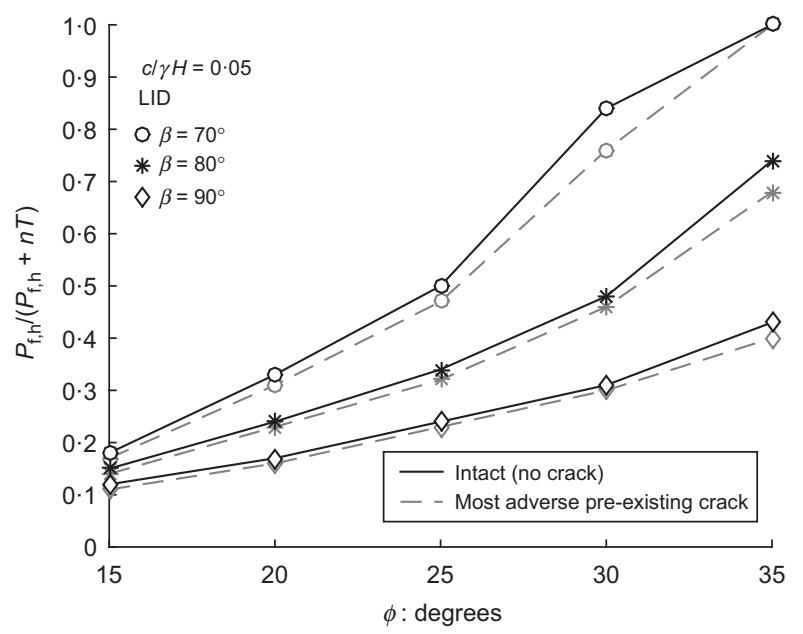

(c)

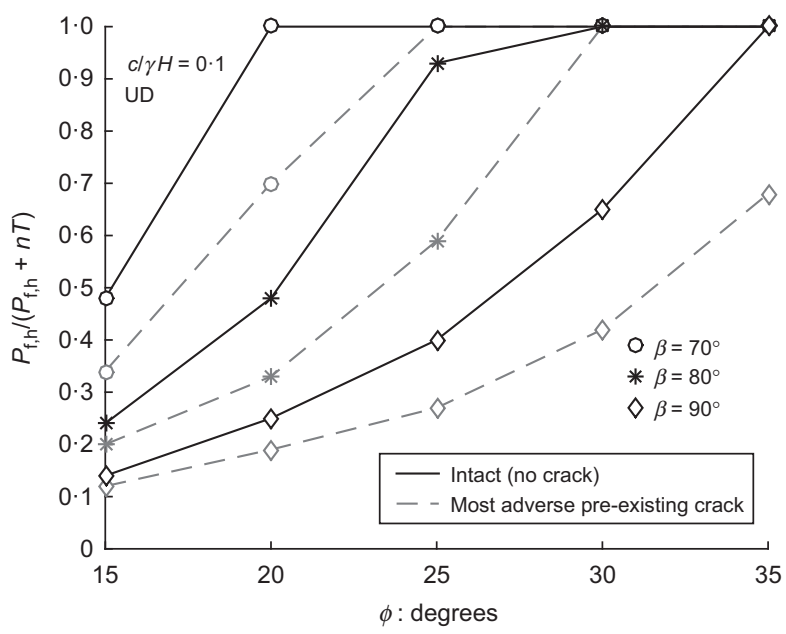

(b)

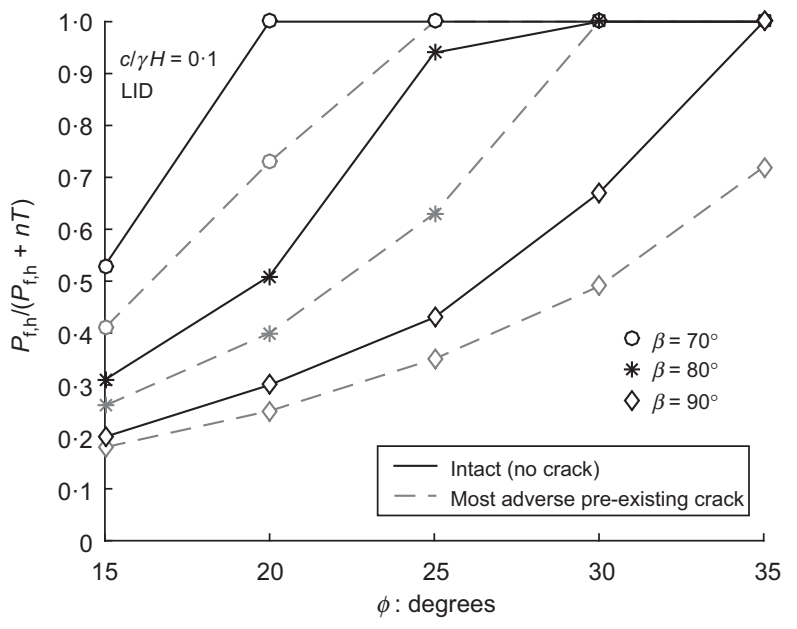

(d)

Fig. 11. Relative horizontal toe resistance contribution $\boldsymbol{P}_{\mathrm{f}, \mathrm{h}} /\left(\boldsymbol{P}_{\mathrm{f}, \mathrm{h}}+\boldsymbol{n} \boldsymbol{T}\right)$ plotted against soil friction angle $\phi$ for a reinforced soil wall in intact soil (black lines) and in the presence of tension cracks (grey lines). The most adverse crack to stability is considered. $\left(\delta=2 / 3 \phi, \delta_{\text {base }}=15^{\circ}\right.$, $\delta_{\mathrm{bb}}=38^{\circ}, L / H=0.7, D=H / 3, w_{\mathrm{b}} / H=0.1$, modified force direction). $P_{\mathrm{f}, \mathrm{h}}$ is the horizontal component of $P_{\mathrm{f}}$. (a) and (b) are for UD distribution, with $c / \gamma H=0.05$ and $c / \gamma H=0.1$, respectively; while (c) and (d) are for LID distribution

required by geosynthetic-reinforced walls in cohesive soils accounting for the contribution of cohesion and wall facing to wall stability and for the onset of tension cracks.

A parametric analysis was performed producing several dimensionless design charts for both uniform and linearly increasing reinforcement distributions. The effects of soil cohesion, soil friction angle, facing batter, block width, location of the reaction force acting on the face, facingbackfill interface friction angle, facing-foundation interface friction angle and reinforcement length were investigated. The results from the parametric analysis showed the following.

(a) Accounting for the presence of cohesion and the facing element can lead to significant savings in the overall level of reinforcement. For normalised cohesion values of $c / \gamma H=0.05$ and $0 \cdot 1$ savings up to $57 \%$ and $82 \%$ of the amount of reinforcement, respectively, could be achieved.

(b) The contribution of the facing to the stability of the structure relies on the facing self-weight and the toe restraint condition. In this study, the toe restraint was accounted for by way of the interface friction between the base of the facing and the foundation soil. The magnitude of this interface friction angle exhibits a major influence on the load capacity of the facing element, being able to drastically reduce the requirement for reinforcement.

(c) The presence of tension cracks has a detrimental effect on wall stability, especially for high values of cohesion. Neglecting the presence of cracks in the design may, therefore, severely underestimate the required reinforcement and possibly risk the safety of the structure.

(d) Adopting common reinforcement lengths employed in the design of reinforced soil walls $(0.6 \mathrm{H}$ and $0.7 \mathrm{H})$, according to the recommendations of many technical standards (e.g. Berg et al., 2009; BSI, 2010; NCMA, 2010; Aashto, 2017), resulted mostly in two types of critical failure modes: internal failure with rupture of all layers of reinforcement and compound failure with the crossed layers failing in tensile rupture and pullout.

This paper has shown the potential for substantial savings to be made on the amount of geo-reinforcement to be employed in reinforced walls by accounting for the contributions of facing and soil cohesion to the structure's stability. These gains can be realised under the condition that a proper drainage system is in place for the cohesive backfill throughout the design lifetime of the wall and the amount of cohesion assumed in the design is conservatively estimated, accounting for its potential degradation over time. 


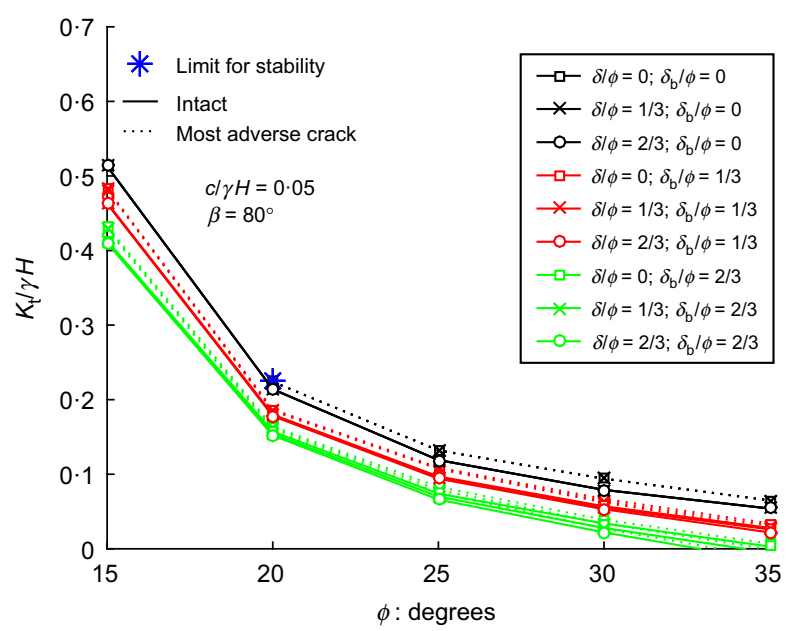

(a)

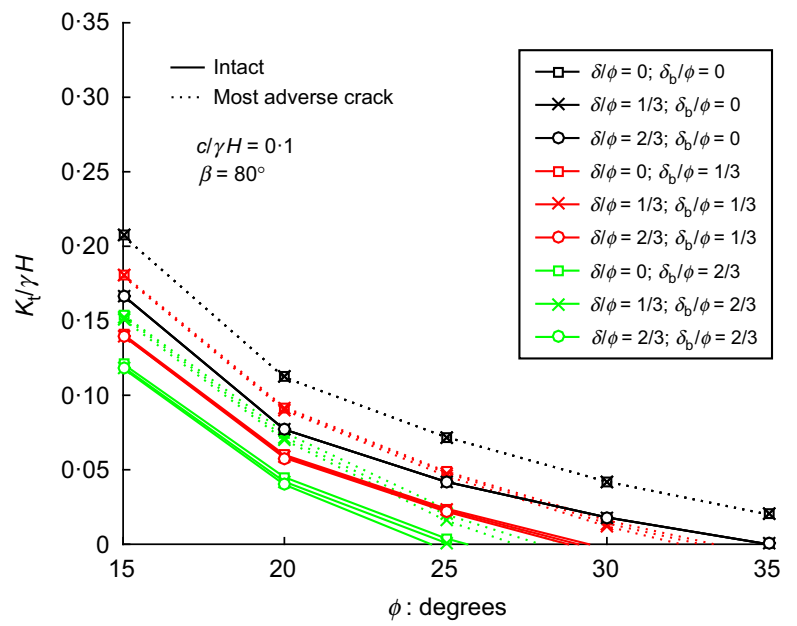

(c)

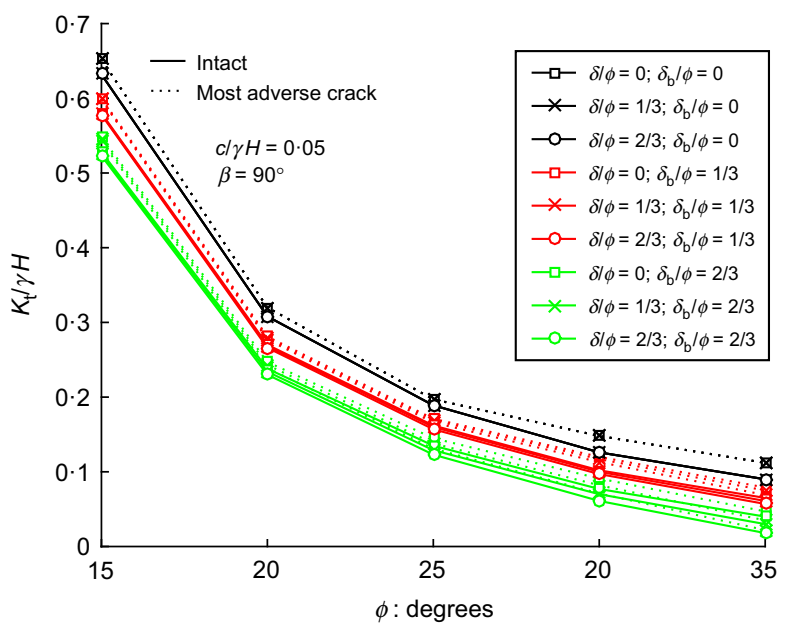

(b)

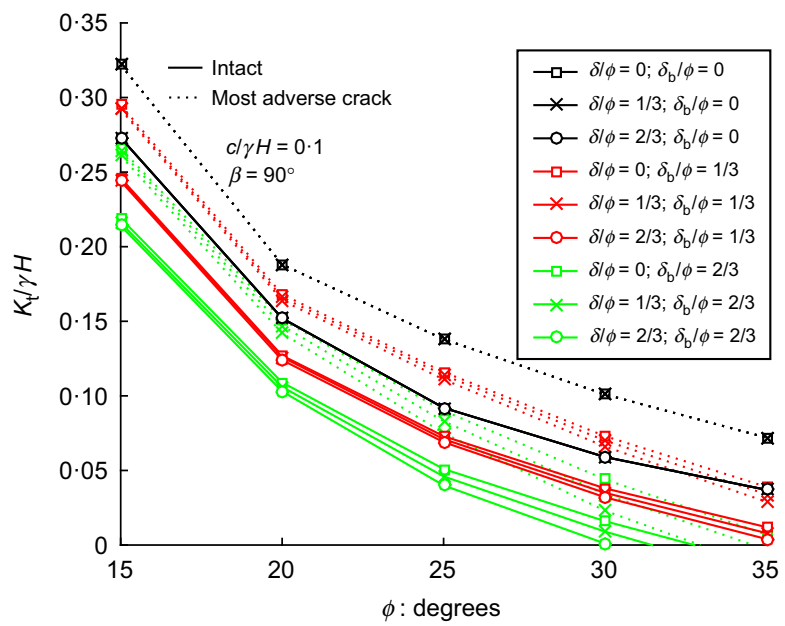

(d)

Fig. 12. Effect of facing-backfill $\delta$ and foundation-block $\delta_{\text {base }}$ interface friction for a reinforced wall in intact soil (black lines) and in the presence of tension cracks (grey lines). The most adverse crack to stability is considered $\left(L / H=0 \cdot 7, \delta_{\mathrm{bb}}=38^{\circ}, w_{\mathrm{b}} / H=0 \cdot 1, D=H / 3\right.$, modified force direction, UD reinforcement distribution). (a) and (b) are for $c / \gamma H=0 \cdot 05$, with $\beta=80^{\circ}$ and $\beta=90^{\circ}$, respectively; while (c) and (d) are for $c / \gamma H=0 \cdot 1$. The '*' markers indicate the limit for stability, beyond which the prescribed reinforcement length is not sufficient to provide stability

\section{ACKNOWLEDGEMENTS}

The authors are grateful to the Brazilian National Council for Scientific and Technological Development $(\mathrm{CNPq})$ and of EU H2020 RISE grant Hercules (778360) for the financial support granted to the first author. They also greatly appreciate the contributions provided by Professor Ben Leshchinsky and the insights of Dr Rafael Plácido on the current field practices related to reinforced soil structures.

\section{APPENDIX 1}

For linearly increasing distribution (LID), the expression for the energy dissipated by the geosynthetics along the log-spiral $\mathrm{C}-\mathrm{F}$ and the crack B-C can be expressed as follows

$$
\begin{aligned}
\dot{D}_{\mathrm{r}(\mathrm{B}-\mathrm{F})}= & \dot{D}_{\mathrm{r}(\mathrm{B}-\mathrm{C})}+\dot{D}_{\mathrm{r}(\mathrm{C}-\mathrm{F})} \\
= & \frac{2}{\left(H / r_{0}\right)} K_{\mathrm{t}} \dot{\theta} r_{0}^{2}\left(\frac{1}{3}\left\{\exp \left[3 \tan \phi\left(\theta_{\mathrm{h}}-\theta_{0}\right)\right] \sin ^{3} \theta_{\mathrm{h}}-\sin ^{3} \theta_{0}\right\}\right. \\
& \left.+\frac{\sin \theta_{0}}{2}\left\{\exp \left[2 \tan \phi\left(\theta_{\mathrm{h}}-\theta_{0}\right)\right] \sin ^{2} \theta_{\mathrm{h}}-\sin ^{2} \theta_{0}\right\}\right) \\
= & K_{\mathrm{t}} \dot{\theta}_{0}^{2} g_{\mathrm{r}}\left(\theta_{0}, \theta_{\mathrm{h}}, \theta_{\mathrm{C}}, \phi\right)
\end{aligned}
$$

If $\sin \theta_{0}+z_{i} / r_{0}<0$, the layers above the centre of rotation are not tensioned so no energy is dissipated in them. Thus, equation (32) simplifies to

$$
\begin{aligned}
\dot{D}_{\mathrm{r}(\mathrm{B}-\mathrm{F})}= & \frac{2}{\left(H / r_{0}\right)} K_{\mathrm{t}} \dot{\theta} r_{0}^{2}\left(\frac{1}{3}\left\{\exp \left[3 \tan \phi\left(\theta_{\mathrm{h}}-\theta_{0}\right)\right] \sin ^{3} \theta_{\mathrm{h}}\right\}\right. \\
& \left.+\frac{\sin \theta_{0}}{2}\left\{\exp \left[2 \tan \phi\left(\theta_{\mathrm{h}}-\theta_{0}\right)\right] \sin ^{2} \theta_{\mathrm{h}}\right\}\right) \\
= & K_{\mathrm{t}} \dot{r}_{0}^{2} g_{\mathrm{r}}\left(\theta_{0}, \theta_{\mathrm{h}}, \phi\right)
\end{aligned}
$$

\section{APPENDIX 2}

The final expressions of the components of the external work rate are given in detail as follows

$$
f_{1}\left(\theta_{0}, \theta_{\mathrm{h}}, \phi\right)=\frac{\left(\mathrm{e}^{3\left(\theta_{\mathrm{h}}-\theta_{0}\right) \tan \phi}\right)\left(3 \tan \phi \cos \theta_{\mathrm{h}}+\sin \theta_{\mathrm{h}}\right)-3 \tan \phi \cos \theta_{0}-\sin \theta_{0}}{3\left(1+9 \tan ^{2} \phi\right)}
$$

$$
\begin{aligned}
f_{2}\left(\theta_{0}, \theta_{\mathrm{h}}, \beta, \phi\right)= & \frac{l_{1}}{6 r_{0}} \sin \theta_{0}\left(2 \cos \theta_{0}-\frac{l_{1}}{r_{0}}\right) \\
f_{3}\left(\theta_{0}, \theta_{\mathrm{h}}, \beta, \phi\right)= & \frac{\mathrm{e}^{\left(\theta_{\mathrm{h}}-\theta_{0}\right) \tan \phi}}{6}\left[\sin \left(\theta_{\mathrm{h}}-\theta_{0}\right)-\frac{l_{1}}{r_{0}} \sin \theta_{\mathrm{h}}\right] \\
& \times\left[\cos \theta_{0}-\frac{l_{1}}{r_{0}}+\cos \theta_{\mathrm{h}}\left(\mathrm{e}^{\left(\theta_{\mathrm{h}}-\theta_{0}\right) \tan \phi}\right)\right]
\end{aligned}
$$




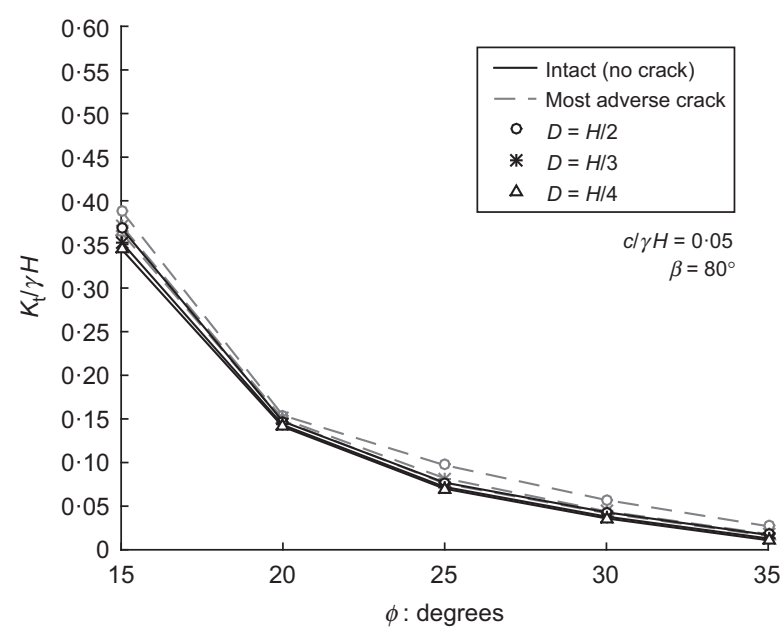

(a)

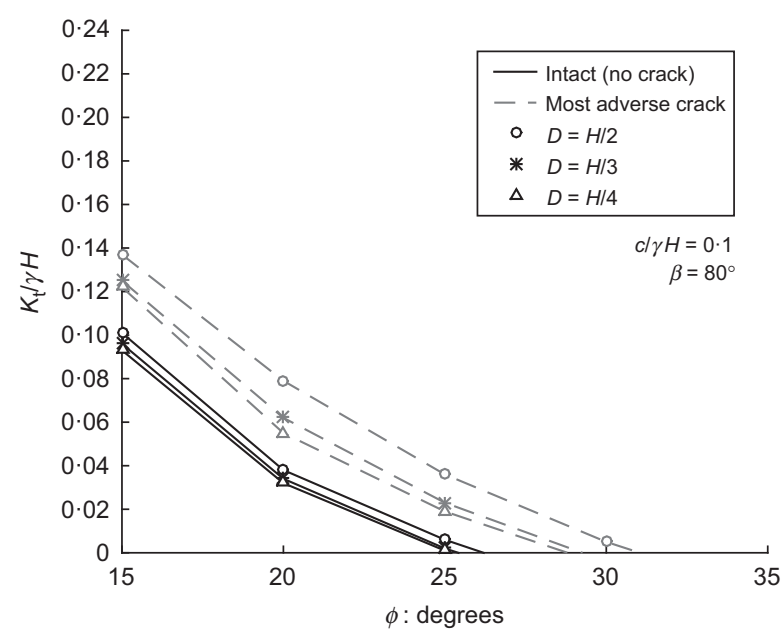

(c)

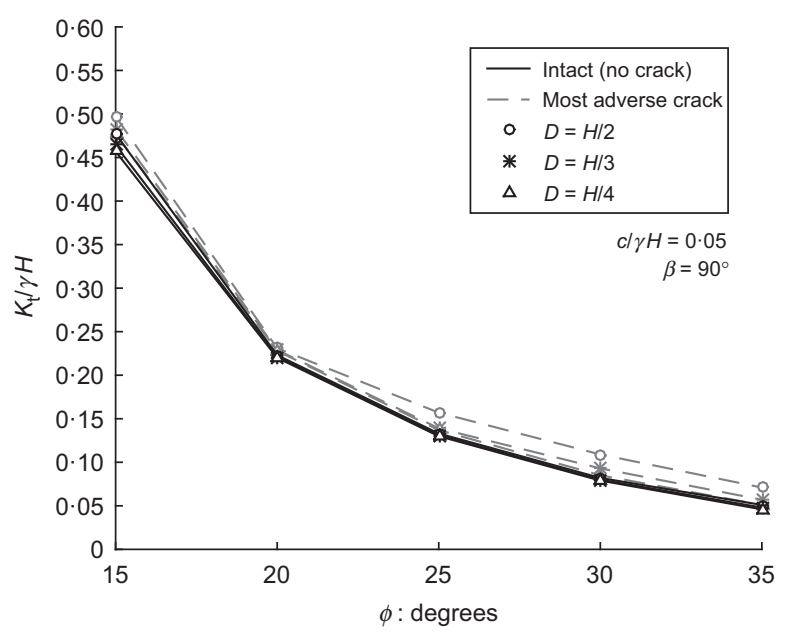

(b)

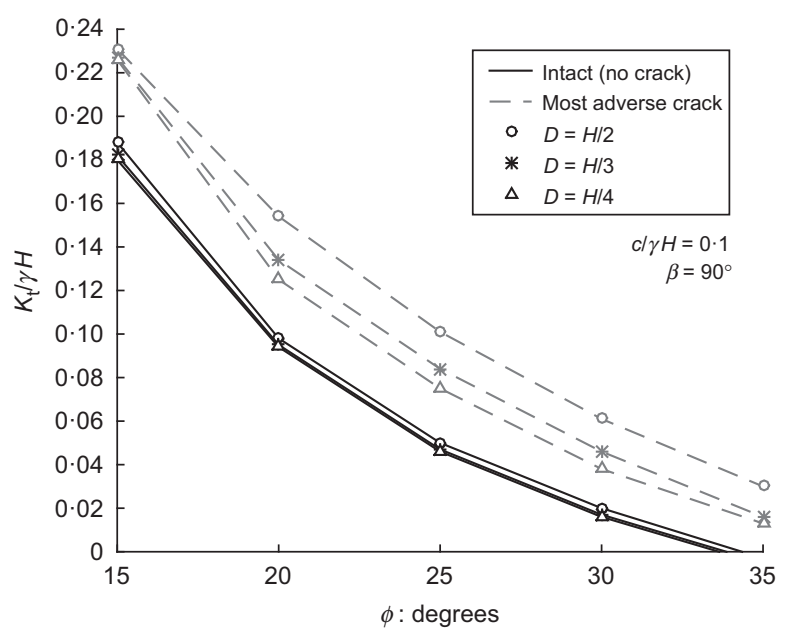

(d)

Fig. 13. Effect of location of the reaction force acting at the facing $(D)$ for a reinforced wall in intact soil (black lines) and in the presence of tension cracks (grey lines). The crack most adverse to stability is assumed. $\left(\phi=20^{\circ}, \delta=2 / 3 \phi, \delta_{\text {base }}=15^{\circ}, \delta_{\mathrm{bb}}=38^{\circ}, L / H=0.7\right.$ and $w_{\mathrm{b}} / H=0 \cdot 1$, modified force direction, UD reinforcement distribution). (a) and (b) are for $c / \gamma H=0 \cdot 05, \beta=80^{\circ}$ and $\beta=90^{\circ}$, respectively, while (c) and (d) are for $c / \gamma H=0 \cdot 1, \beta=80^{\circ}$ and $\beta=90^{\circ}$, respectively

$$
\begin{aligned}
& f_{4}\left(\theta_{0}, \theta_{\mathrm{C}}, \phi\right)=\frac{\mathrm{e}^{3\left(\theta_{\mathrm{C}}-\theta_{0}\right) \tan \phi}+\left(3 \tan \phi \cos \theta_{\mathrm{C}}+\sin \theta_{\mathrm{C}}\right)-3 \tan \phi \cos \theta_{0}-\sin \theta_{0}}{3\left(1+9 \tan ^{2} \phi\right)} \\
& f_{5}\left(\theta_{0}, \theta_{\mathrm{C}}, \phi\right)=\frac{l_{2}}{6 r_{0}} \sin \theta_{0}\left(2 \cos \theta_{0}-\frac{l_{2}}{r_{0}}\right) \\
& f_{6}\left(\theta_{0}, \theta_{\mathrm{C}}, \phi\right)=\frac{\mathrm{e}^{2\left(\theta_{\mathrm{C}}-\theta_{0}\right) \tan \phi} \cos ^{2} \theta_{\mathrm{C}}}{3}\left(\mathrm{e}^{\left(\theta_{C}-\theta_{0}\right) \tan \phi} \sin \theta_{\mathrm{C}}-\sin \theta_{0}\right)
\end{aligned}
$$

$$
\begin{aligned}
& f_{\mathrm{w}}\left(\theta_{0}, \theta_{\mathrm{h}}, \theta_{\mathrm{C}}, \phi\right)= \\
& \quad \frac{1}{r_{0}^{3}}\left(\int_{\theta_{\mathrm{w}}}^{\theta_{\mathrm{c}}} z_{\mathrm{c}} r_{\mathrm{BC}}^{2} \tan \theta \mathrm{d} \theta+\int_{\theta_{\mathrm{C}}}^{\theta_{1-2}} z_{1} r^{2} \tan \phi \mathrm{d} \theta+\int_{\theta_{1-2}}^{\theta_{h}} z_{2} r^{2} \tan \phi \mathrm{d} \theta\right)
\end{aligned}
$$

where $r$ is given in equation (3) and $r_{\mathrm{BC}}$ by the following expression

$$
\begin{aligned}
& r_{\mathrm{BC}}=\frac{r_{\mathrm{C}} \cos \theta_{\mathrm{C}}}{\cos \theta} \\
& z_{\mathrm{c}}, z_{1} \text { and } z_{2} \text { are given below: } \\
& z_{\mathrm{c}}=r_{0}\left\{\exp \left[\tan \phi\left(\theta_{\mathrm{C}}-\theta_{0}\right)\right] \cos \theta_{\mathrm{C}} \tan \theta-\sin \theta_{0}\right\}
\end{aligned}
$$

$$
\begin{aligned}
z_{1}= & r_{0}\left\{\exp \left[\tan \phi\left(\theta-\theta_{0}\right)\right] \sin \theta-\sin \theta_{0}\right\} \\
z_{2}= & r_{0}\left(\exp \left[\tan \phi\left(\theta-\theta_{0}\right)\right] \sin \theta\right. \\
& -\left\{\exp \left[\tan \phi\left(\theta_{1-2}-\theta_{0}\right)\right] \cos \theta_{1-2}\right. \\
& \left.\left.-\exp \left[\tan \phi\left(\theta-\theta_{0}\right)\right] \cos \theta\right\} \tan \beta-\sin \theta_{0}\right)
\end{aligned}
$$

The angle $\theta_{1-2}$ is determined from

$$
\begin{aligned}
& \exp \left[\tan \phi\left(\theta_{1-2}-\theta_{0}\right)\right] \cos \theta_{1-2}-\cos \theta_{0}+\frac{l_{1}}{r_{0}}=0 \\
& \theta_{1-2} \in\left[\theta_{0}, \theta_{\mathrm{h}}\right]
\end{aligned}
$$

Note that the previous expression has two solutions and the one to be taken is the value ranging from $\theta_{0}$ to $\theta_{\mathrm{h}}$.

The term related to the work rate of the facing contribution, for the conventional direction and for a force acting at $D=H / \lambda$ from the wall toe (generalisation of the expression given by Li \& Yang $(2018,2019))$ is given by

$$
\begin{gathered}
f_{7}\left(\theta_{0}, \theta_{\mathrm{h}}, \beta, \delta, \lambda, \phi\right)=\sin (\beta+\delta)\left[\sin \theta_{0}+\frac{(\lambda-1)}{\lambda} \frac{H}{r_{0}}\right] \\
-\cos (\beta+\delta)\left\{\exp \left[\tan \phi\left(\theta_{\mathrm{h}}-\theta_{0}\right)\right] \cos \theta_{\mathrm{h}}+\frac{1}{\lambda} \frac{H}{r_{0}} \cot \beta\right\}
\end{gathered}
$$


where $H$ is the wall height and $\lambda$ is a dimensionless term larger than 1 .

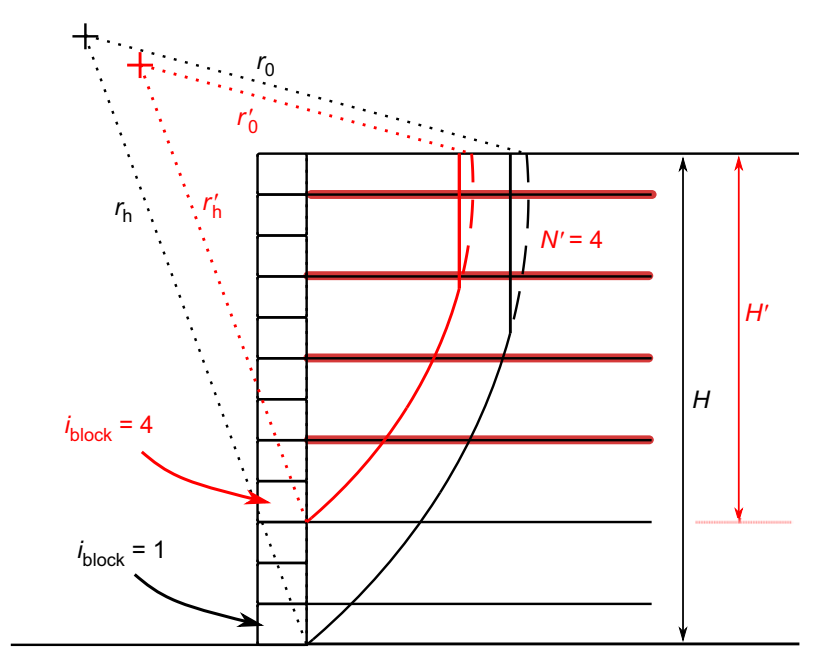

Fig. 14. Schematic representation of the failure surface emerging at the wall facing and relevant notation

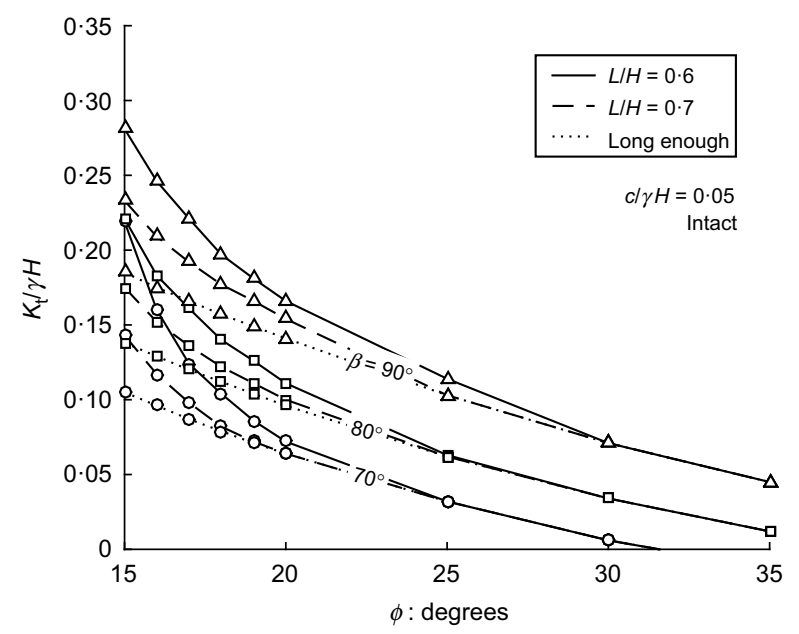

(a)

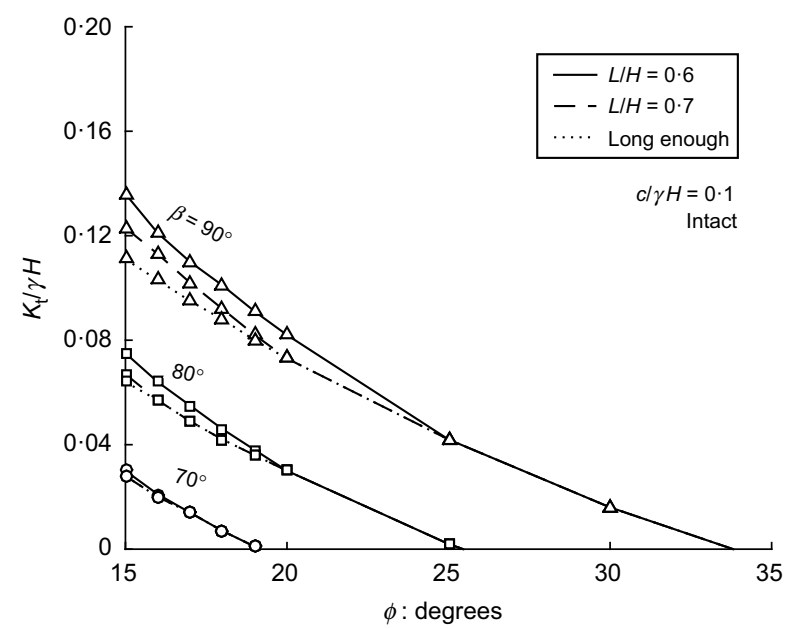

(c)
For the modified direction, the following expression applies (generalisation of the expression given by Xie et al. (2016))

$$
\begin{aligned}
f_{7}\left(\theta_{0}, \theta_{\mathrm{h}}, \beta, \delta, \lambda, \phi\right)= & \sin \delta\left\{\exp \left[\tan \phi\left(\theta_{\mathrm{h}}-\theta_{0}\right)\right] \cos \theta_{\mathrm{h}}+\frac{1}{\lambda} \frac{H}{r_{0}} \cot \beta\right\} \\
& +\cos \delta\left\{\exp \left[\tan \phi\left(\theta_{\mathrm{h}}-\theta_{0}\right)\right] \sin \theta_{\mathrm{h}}-\frac{1}{\lambda} \frac{H}{r_{0}}\right\}
\end{aligned}
$$

\section{APPENDIX 3}

When considering failure mechanisms emerging at the wall facing, equations (17) and (21) need to be modified to account for the reduced height $H^{\prime}$ of the failure mechanism

$$
\begin{aligned}
& H^{\prime}=H\left[1-\frac{\left(i_{\text {block }}-1\right)}{N_{\mathrm{b}}}\right], i_{\text {block }}: 1 \rightarrow N_{\mathrm{b}} \\
& H^{\prime}=H \times \Omega
\end{aligned}
$$

where $\Omega$ is the height factor, $i_{\text {block }}$ identifies the block immediately above the block-block interface intersected by the failure mechanism (Fig. 14) and $N_{\mathrm{b}}$ is the number of facing blocks.

For a partial wall height, only the weight of the column of blocks above the block-block interface considered contributes to the stability; therefore, the reaction force acting on the facing element is given by $P_{\mathrm{f}}^{\prime}$

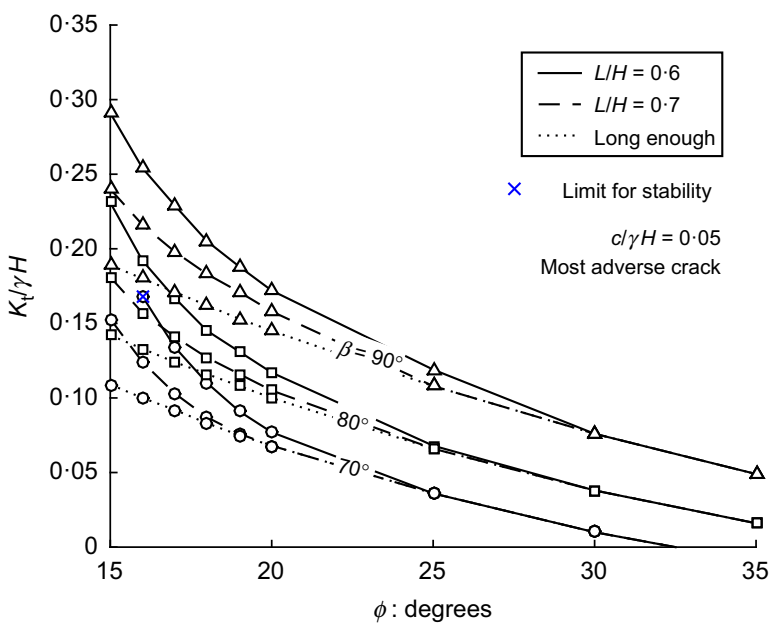

(b)

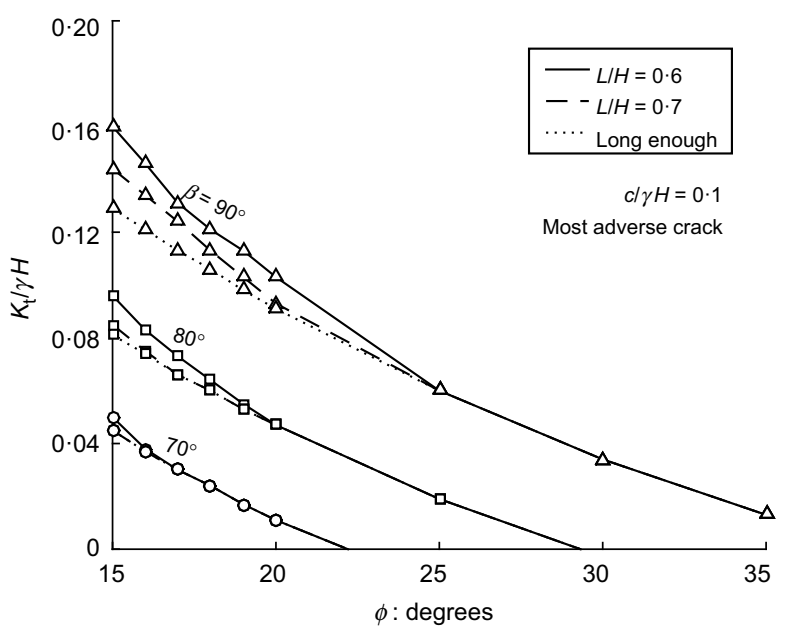

(d)

Fig. 15. Required reinforcement versus soil friction angle $\phi$ for three values of wall facing batter, $\beta$, and for different $L / H$ (sufficient length for rupture of all layers, $0.6 \mathrm{H}$ and $0.7 \mathrm{H})\left(w_{\mathrm{b}} / H=0.1, \delta=2 / 3 \phi, \delta_{\text {base }}=15^{\circ}, \delta_{\mathrm{bb}}=38^{\circ}, D=H / 3\right.$, modified force direction, LID reinforcement distribution). (a) and (b) are for a reinforced soil wall in intact soil and in the presence of tension cracks for $c / \gamma H=0.05$, respectively; while (c) and (d) are for $c / \gamma H=0 \cdot 1$. The most adverse crack to stability is considered. The ' $x$ ' marker indicates the limit for stability, beyond which the prescribed reinforcement length is not sufficient to provide stability 


$$
\frac{P_{\mathrm{f}}^{\prime}}{\gamma H^{2}}=\frac{\Omega\left(\gamma_{\mathrm{b}} / \gamma\right)\left(w_{\mathrm{b}} / H\right) \tan \delta_{\mathrm{bb}}}{\cos \delta_{\mathrm{h}}-\sin \delta_{\mathrm{h}} \tan \delta_{\mathrm{bb}}}
$$

where $\delta_{\mathrm{bb}}$ is the interface friction angle between two adjacent blocks.

The objective function given in equation (17) becomes

$$
\frac{K_{\mathrm{t}}}{\gamma H}=\frac{\Omega\left(f_{1}-f_{2}-f_{3}-f_{4}+f_{5}+f_{6}+r_{\mathrm{u}} f_{\mathrm{w}}\right)}{\left(H^{\prime} / r_{0}^{\prime}\right)\left(g_{\mathrm{r}}\right)}-\frac{c}{\gamma H}\left(\frac{g_{\mathrm{s}}}{g_{\mathrm{r}}}\right)-\frac{1}{\Omega}\left(\frac{H^{\prime}}{r_{0}^{\prime}}\right) \frac{P_{\mathrm{f}}^{\prime}}{\gamma H^{2}} \frac{f_{7}}{\left(g_{\mathrm{r}}\right)}
$$

$$
\frac{K_{\mathrm{t}}}{\gamma H}=f\left(\theta_{0}, \theta_{\mathrm{h}}, \theta_{\mathrm{C}}, \beta, r_{\mathrm{u}}, \phi, c / \gamma H, \delta, D, w_{\mathrm{b}} / H, \delta_{\mathrm{base}}, \delta_{\mathrm{bb}}, \Omega\right)
$$

The objective function given in equation (21), for a combined failure mechanism (rupture and pullout), becomes where $N^{\prime}$ is the number of reinforcement layers crossed above the intersection between the failure surface and the wall facing (Fig. 14). $H^{\prime}$ and $r_{0}^{\prime}$ are the geometric parameters related to the failure surface emerging at the wall facing as depicted in Fig. 14.

$$
\begin{aligned}
\frac{K_{\mathrm{t}}}{\gamma H}= & \frac{\Omega\left(r_{0}^{\prime} / H^{\prime}\right)^{2}\left(f_{1}-f_{2}-f_{3}-f_{4}+f_{5}+f_{6}+r_{\mathrm{u}} f_{\mathrm{w}}\right)-\left(r_{0}^{\prime} / H^{\prime}\right)(c / \gamma H)\left(g_{\mathrm{s}}\right)}{1 / N^{\prime}\left\{\sum_{\text {rupture }}\left[\sin \theta_{0}+\left(z_{(i)} / r_{0}^{\prime}\right)\right]\right\}} \\
& +\frac{(1 / \Omega)\left(P_{\mathrm{f}}^{\prime} / \gamma H^{2}\right) f_{7}-2 f_{\mathrm{b}} \tan \phi\left(1-r_{\mathrm{u}}\right) \sum_{\text {pullout }}\left\{\Omega\left(z_{(i)}^{*} / H^{\prime}\right)\left(L_{\mathrm{e}(i)} / H^{\prime}\right)\left[\sin \theta_{0}+\left(z_{(i)} / r_{0}^{\prime}\right)\right]\right\}}{1 / N^{\prime}\left\{\sum_{\text {rupture }}\left[\sin \theta_{0}+\left(z_{(i)} / r_{0}^{\prime}\right)\right]\right\}}
\end{aligned}
$$

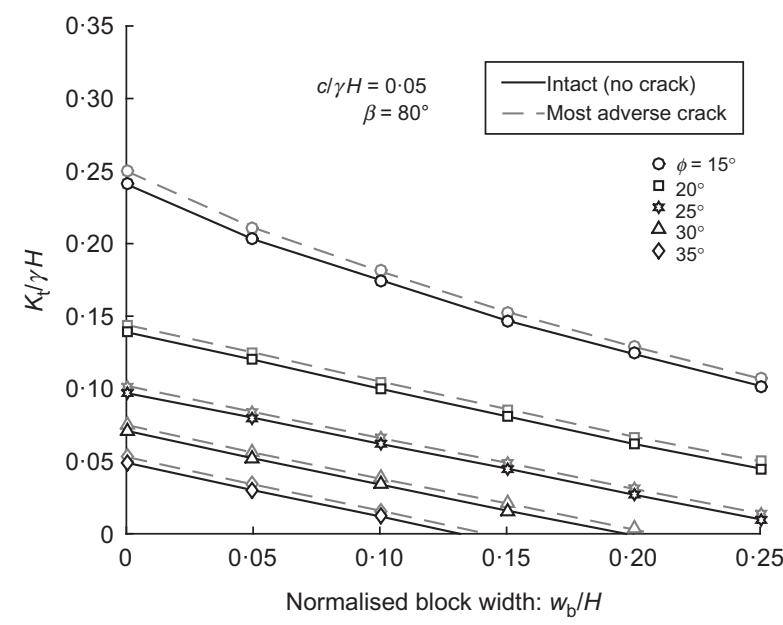

(a)

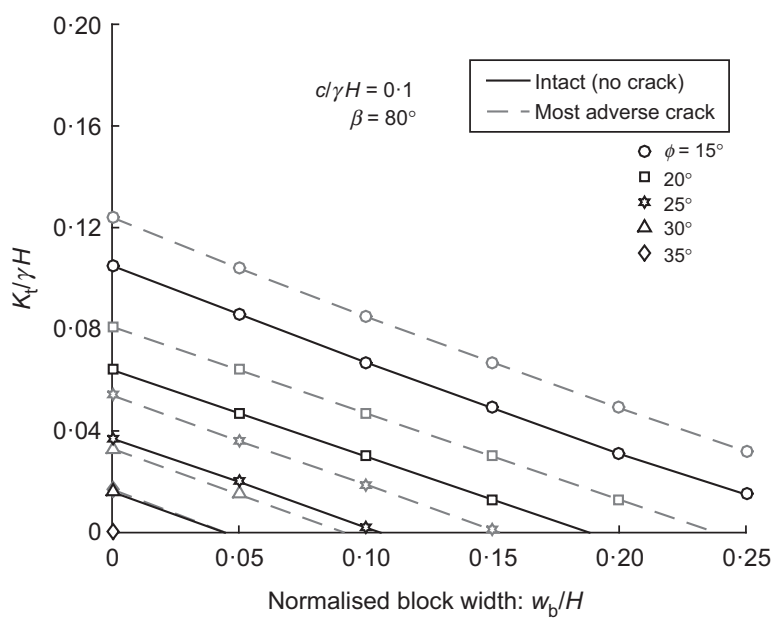

(c)

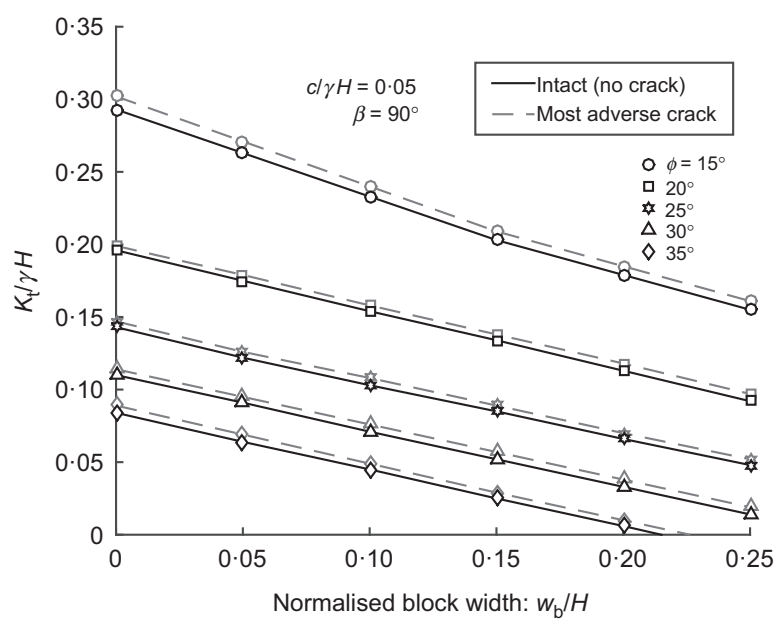

(b)

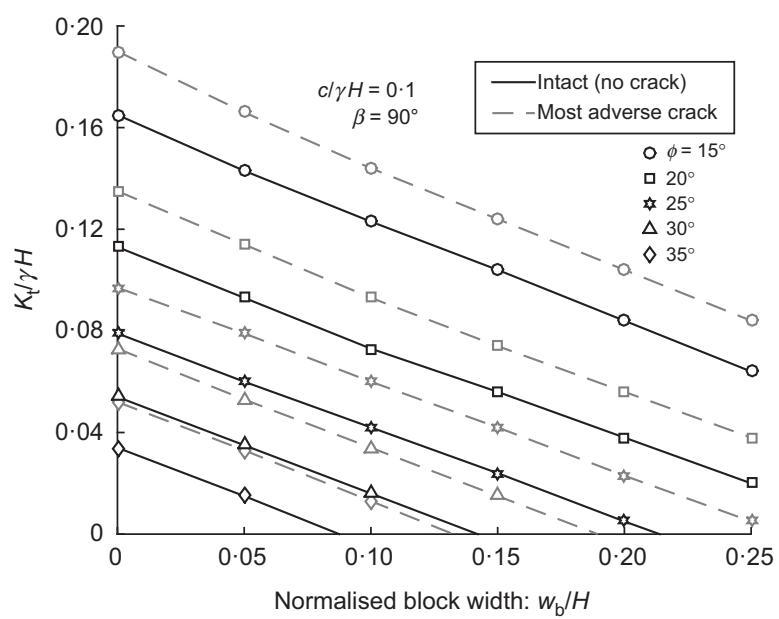

(d)

Fig. 16. Required reinforcement plotted against $w_{\mathrm{b}} / H$ for a reinforced soil wall in intact soil and in the presence of tension cracks. The most adverse crack to stability is considered. (a) and (b) are for $c / \gamma H=0.05$ with $\beta=80^{\circ}$ and $\beta=90^{\circ}$, respectively; while (c) and (d) are for $c / \gamma H=0 \cdot 1$ with $\beta=80^{\circ}$ and $\beta=90^{\circ}$, respectively. $\left(\delta=2 / 3 \phi, \delta_{\text {base }}=15^{\circ}, \delta_{\mathrm{bb}}=38^{\circ}, L / H=0 \cdot 7, D=H / 3\right.$, modified force direction, LID reinforcement distribution) 


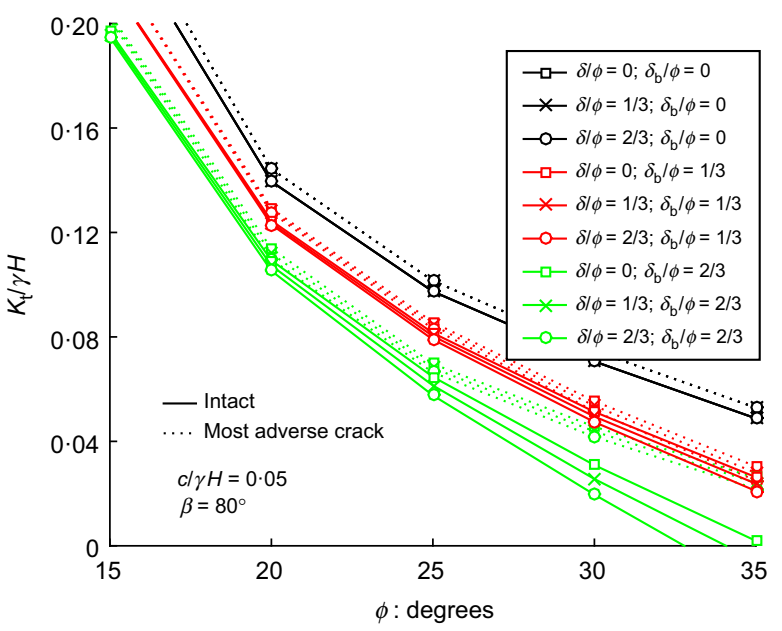

(a)

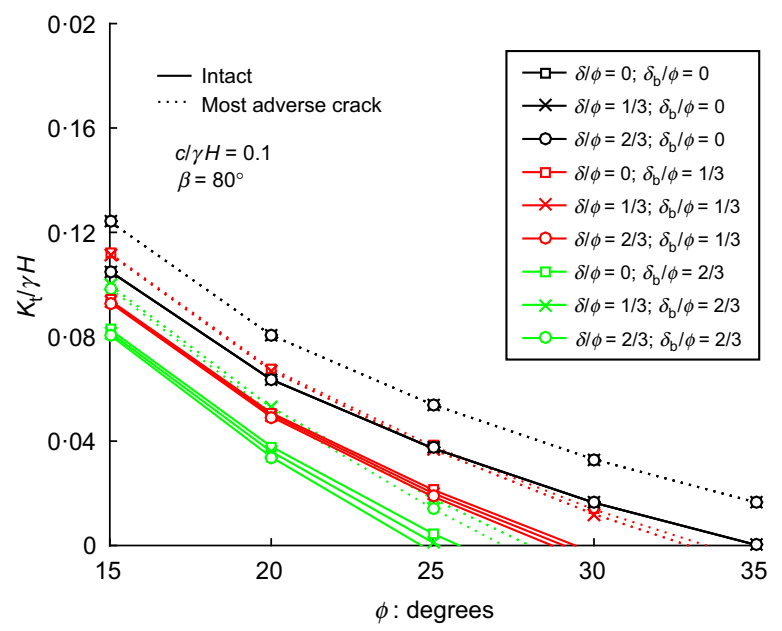

(c)

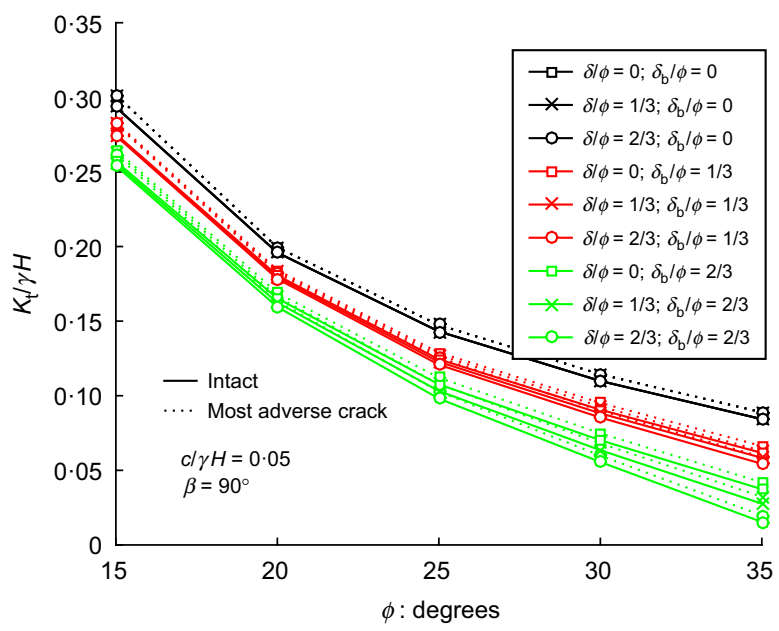

(b)

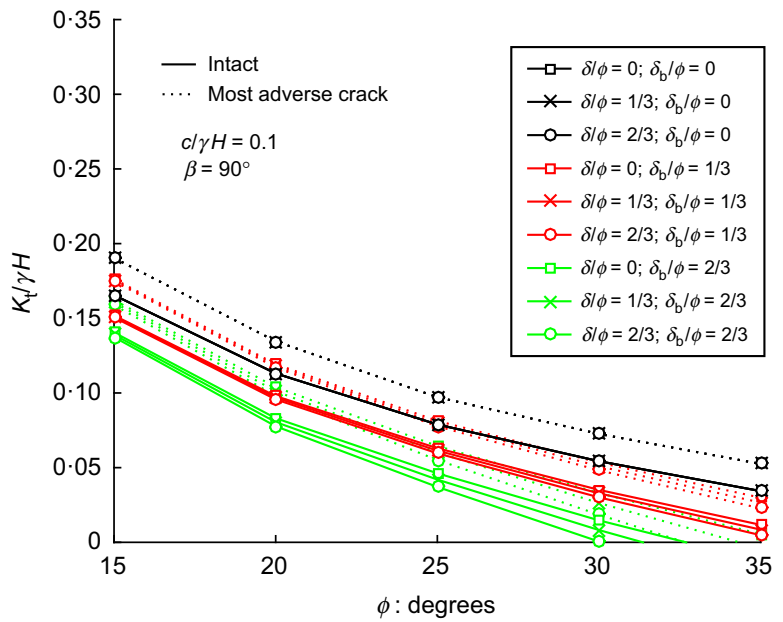

(d)

Fig. 17. Effect of facing-backfill $\delta$ and foundation-block $\delta_{\text {base }}$ interface friction for a reinforced wall in intact soil (solid lines) and in the presence of tension cracks (dashed lines). The most adverse crack to stability is considered $\left(L / H=0 \cdot 7, \delta_{\mathrm{bb}}=38^{\circ}, w_{\mathrm{b}} / H=0 \cdot 1, D=H / 3\right.$, modified force direction, LID reinforcement distribution). (a) and (b) are for $c / \gamma H=0.05$, with $\beta=80^{\circ}$ and $\beta=90^{\circ}$, respectively; while (c) and (d) are for $c / \gamma H=0 \cdot 1$

\section{APPENDIX 4}

See Figs $15-18$.

\section{NOTATION}

$c$ cohesion

$\dot{D}$ total energy dissipation rate

$D$ vertical distance between the wall force location and the wall toe

$D_{\mathrm{r}} \quad$ energy dissipation rate within the reinforcement

$D_{\mathrm{s}}$ energy dissipation rate within the soil

$f_{1}, f_{2}, \ldots, f_{6}$ functions to calculate the external work rate made by soil weight

$f_{7}$ non-dimensional function to calculate the external work rate done by facing element

$f_{\mathrm{b}}$ bond coefficient between soil and geosynthetic reinforcement

$f_{\mathrm{w}}$ function to evaluate external work rate done by the pore-water pressure

$G_{\mathrm{f}} \quad$ wall facing self-weight

$g_{\mathrm{r}}$ function for dissipated energy rate created by the reinforcement along $\mathrm{B}-\mathrm{C}$ and $\mathrm{C}-\mathrm{F}$

$g_{\text {s }}$ function for dissipated energy rate created by the soil along the log-spiral slip surface $(\mathrm{C}-\mathrm{F})$

$H$ wall height

$h_{\mathrm{b}}$ block height

$i$ the $i$ th layer of reinforcement $i_{\text {block }}$ identification of block immediately above the inter-block interface intersected by the failure mechanism

$K$ generic average tensile strength of reinforcement

$K_{\mathrm{t}}$ average tensile strength of a uniformly distributed reinforcement

$L$ total length of the reinforcement layers

$L_{\mathrm{a}}(i)$ active length of reinforcement layer $i$

$L_{\mathrm{c}(i)} \quad$ length of reinforcement layer $i$ as illustrated in Fig. 3

$L_{\mathrm{e}(i)} \quad$ effective length of reinforcement layer $i$ resisting pull-out failure

$l_{1}, l_{2}$ lengths defined in Fig. 3

$N$ number of geosynthetic layers

$N_{0} \quad$ number of reinforcement layers above the exit point of the failure surface at the wall facing

$N_{\mathrm{b}} \quad$ number of facing blocks

$P_{\mathrm{f}}$ reaction force acting on the facing element

$P_{\mathrm{f}, \mathrm{h}}$ horizontal component of reaction force acting on the wall facing

$P_{\mathrm{f}, \mathrm{s}} \quad$ shear component of reaction force acting on the wall facing

$P_{\text {pullout }} \quad$ summation of layers failing by pullout

$P_{\text {rupture }}$ summation of layers failing in tensile rupture

$R_{\mathrm{h}} \quad$ horizontal force acting at the wall toe

$R_{\mathrm{V}} \quad$ normal force acting at base of the facing

$r$ generic radius for the log-spiral slip surface $(\mathrm{C}-\mathrm{F})$ 


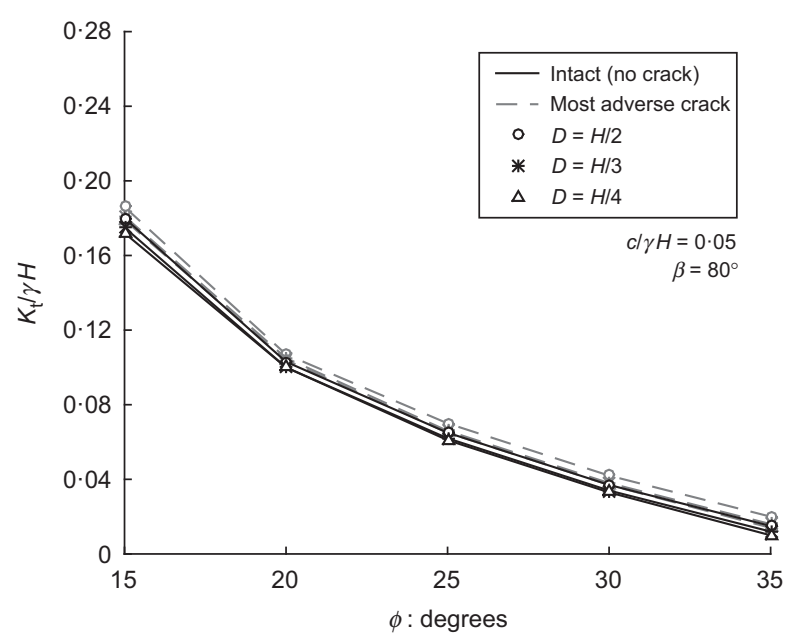

(a)

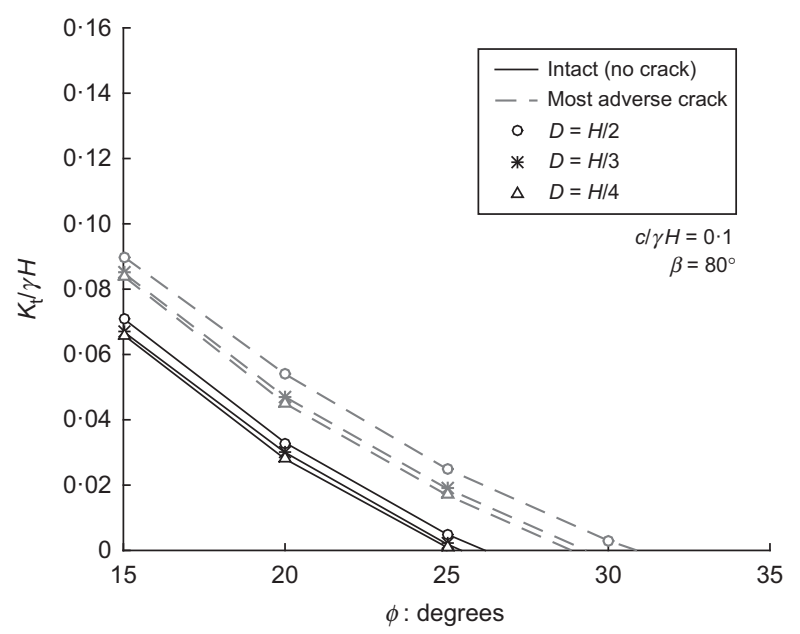

(c)

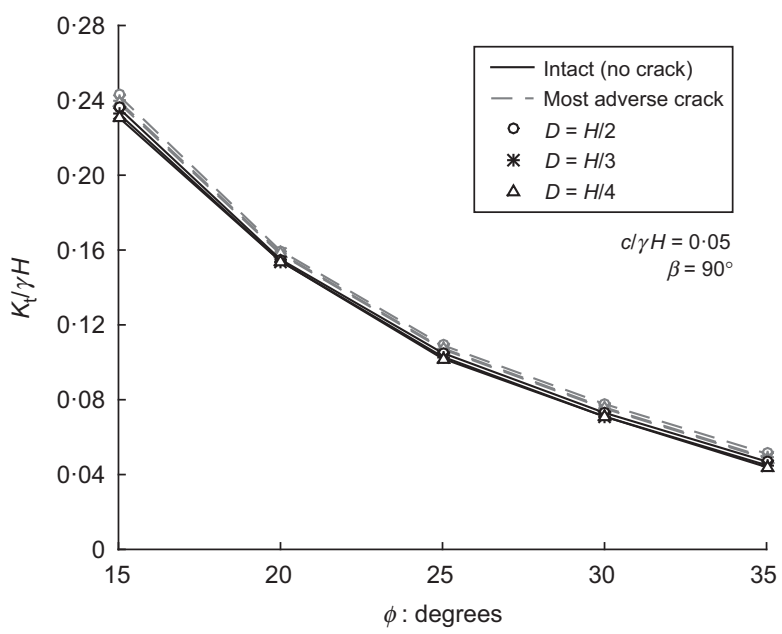

(b)

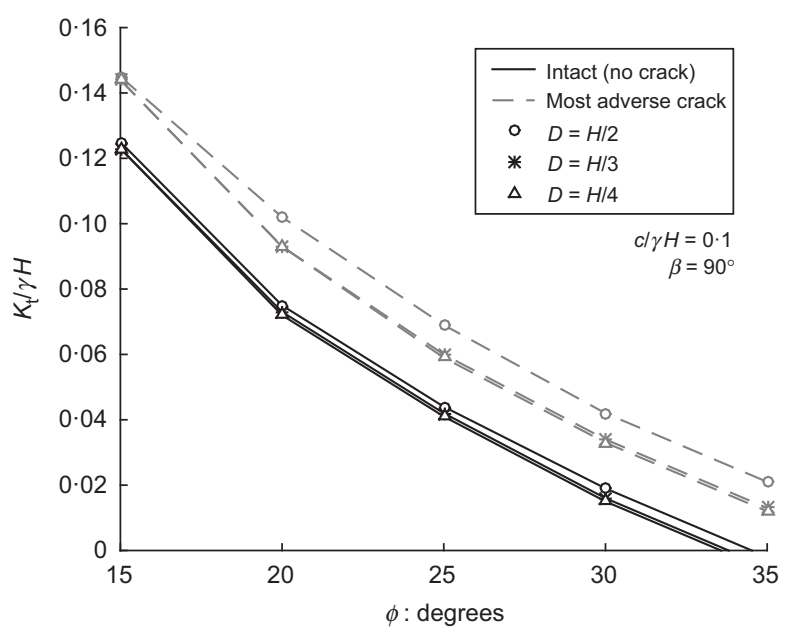

(d)

Fig. 18. Effect of location of the reaction force acting at the facing $(D)$ for a reinforced wall in intact soil (black lines) and in the presence of tension cracks (grey lines). The crack most adverse to stability is assumed. $\left(\phi=20^{\circ}, \delta=23 \phi, \delta_{\text {base }}=15^{\circ}, \delta_{\mathrm{bb}}=38^{\circ}, L / H=0.7\right.$ and $w_{\mathrm{b}} / H=0 \cdot 1$, modified force direction, LID reinforcement distribution). (a) and (b) are for $c / \gamma H=0.05$, with $\beta=80^{\circ}$ and $\beta=90^{\circ}$, respectively, while (c) and (d) are for $c / \gamma H=0 \cdot 1$, with $\beta=80^{\circ}$ and $\beta=90^{\circ}$, respectively

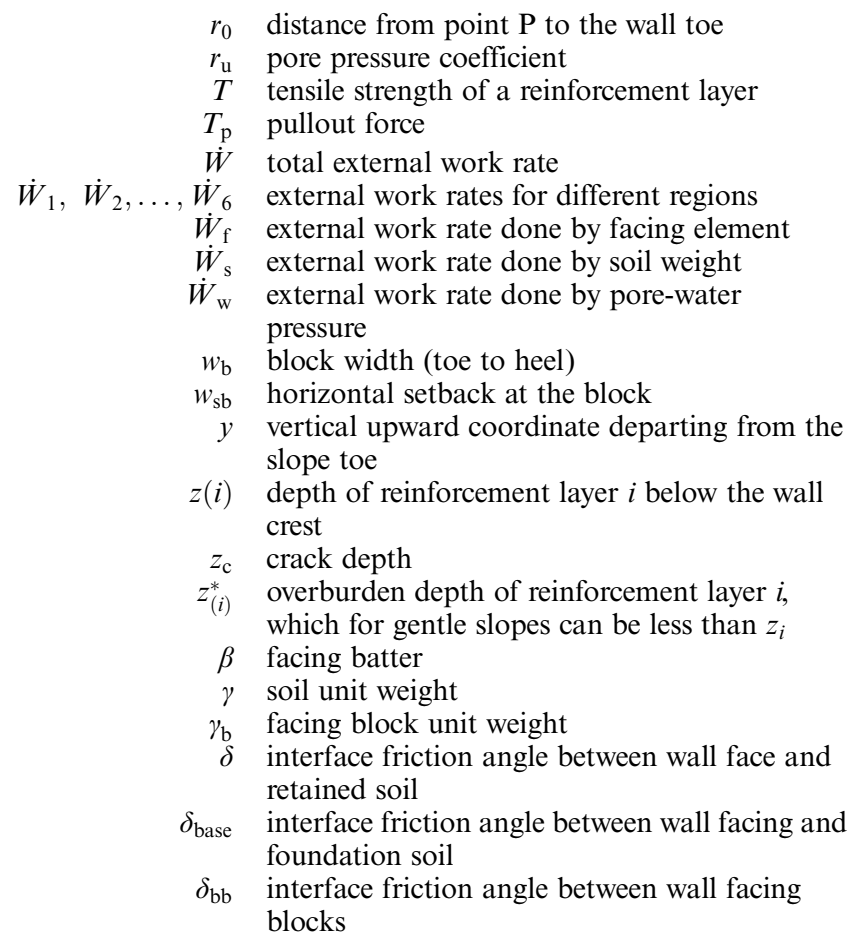

$\delta_{\mathrm{h}} \quad$ interface friction angle between facing and retained soil with respect to the horizontal

$\theta$ generic angle of the log-spiral part of the failure surface

$\dot{\theta} \quad$ angular velocity of sliding soil mass

$\theta(i)$ angle related to the intersection of the failure surface with the $i$-layer

$\theta_{0} \quad$ angle between line $\mathrm{P}-\mathrm{A}$ and the horizontal

$\theta_{\mathrm{C}} \quad$ angle between line $\mathrm{P}-\mathrm{C}$ and the horizontal

$\theta_{\mathrm{h}}$ angle between line $\mathrm{P}-\mathrm{F}$ and the horizontal

$\lambda$ dimensionless term larger than 1 representing position of reaction force at the wall

$\phi \quad$ soil internal friction angle

$\psi \quad$ ratio between horizontal force on wall toe and total force carried by all reinforcement layers

$\Omega$ height factor for failure mechanisms emerging at the wall facing

\section{REFERENCES}

Aashto (American Association of State Highway and Transportation Officials) (2012). LRFD bridge design specifications, 6th edn. Washington, DC, USA: American Association of State Highway and Transportation Officials.

Aashto (2017). LRFD bridge design specifications, 8th edn. Washington, DC, USA: American Association of State Highway and Transportation Officials. 
Abd, A. H. \& Utili, S. (2017). Design of geosynthetic-reinforced slopes in cohesive backfills. Geotext. Geomembr. 45, No. 6, 627-641, https://doi.org/10.1016/j.geotexmem.2017.08.004.

Allen, T. M. \& Bathurst, R. J. (2014a). Design and performance of 6.3-m-high, block-faced geogrid wall designed using $k$-stiffness method. J. Geotech. Geoenviron. Engng 140, No. 2, 04013016, https://doi.org/10.1061/(ASCE)GT.1943-5606.0001013.

Allen, T. M. \& Bathurst, R. J. (2014b). Performance of an $11 \mathrm{~m}$ high block-faced geogrid wall designed using the K-stiffness method. Can. Geotech. J. 51, No. 1, 16-29, https://doi.org/10. 1139/cgj-2013-0261.

Anderson, D. G., Martin, G. R., Lam, I. P. \& Wang, J. N. (2008). Seismic analysis and design of retaining walls, slopes and embankments, and buried structures, NCHRP Report 611. Washington, DC, USA: Transportation Research Board.

ASTM (2018a). D6638-18: Standard test method for determining connection strength between geosynthetic reinforcement and segmental concrete units (modular concrete blocks). West Conshohocken, PA, USA: ASTM International.

ASTM (2018b). D6916-18: Determining the shear strength between segmental concrete units (modular concrete blocks). West Conshohocken, PA, USA: ASTM International.

Baker, R. (1981). Tensile strength, tension cracks, and stability of slopes. Soils Found. 21, No. 2, 1-17.

Baker, R. \& Klein, Y. (2004). An integrated limiting equilibrium approach for design of reinforced soil retaining structures: part I - formulation. Geotext. Geomembr. 22, No. 3, 119-150, https://doi.org/10.1016/j.geotexmem.2003.10.002.

Bathurst, R. J. (1993). Investigation of footing restraint on stability of large-scale reinforced soil wall tests. 46th Canadian geotechnical conference, Saskatoon, Canada, pp. 389-398.

Bathurst, R. J. \& Walters, D. L. (2000). Lessons learned from full scale testing of geosynthetic reinforced soil retaining walls. Geoeng2000, Melbourne, Australia.

Bathurst, R. J., Simac, M. R. \& Berg, R. R. (1993a). Review of NCMA segmental retaining wall design manual for geosynthetic reinforced structures. Transp. Res. Rec. 1414, 16-25.

Bathurst, R. J., Simac, M. R., Christopher, B. R. \& Bonczkiewicz, C. (1993b). A database of results from a geosynthetic reinforced modular block soil retaining wall. In Proceedings of soil reinforcement: full scale experiments of the 80s, ISSMFE/ ENPC, pp. 341-365. Paris, France: Presses de l'École Nationale des Ponts et Chausées.

Bathurst, R. J., Vlachopoulos, N., Walters, D. L., Burgess, P. \& Allen, T. M. (2006). The influence of facing stiffness on the performance of two geosynthetic reinforced soil retaining walls. Can. Geotech. J. 43, No. 12, 1225-1237, https://doi.org/ 10.1139/t06-076.

Bathurst, R. J., Althoff, S. \& Linnenbaum, P. (2008). Influence of test method on direct shear behavior of segmental retaining wall units. Geotech. Test. J. 31, No. 2, 157-165, https://doi.org/ 10.1520/gtj100911.

Berg, R. R., Christopher, B. R. \& Samtani, N. C. (2009). Design and construction of mechanically stabilized earth walls and reinforced soil slopes, FHWA-NHI-10-024, vol. I. Washington, DC, USA: Federal Highway Administration (FHWA).

Bishop, A. W. \& Morgenstern, N. (1960). Stability coefficients for earth slopes. Géotechnique 10, No. 4, 129-153, https://doi.org/ 10.1680/geot.1960.10.4.129.

BSI (2010). BS 8006-1:2010+A1:2016: Code of practice for strengthened/reinforced soils and other fills. London, UK: BSI.

BSI (2019). BS 5975:2019: Code of practice for temporary works procedures and the permissible stress design of falsework. London, UK: BSI.

Buhan, P., Mangiavacchi, R., Nova, R., Pellegrini, G. \& Salençon, J. (1989). Yield design of reinforced earth walls by a homogenization method. Géotechnique 39, No. 2, 189-201, https://doi.org/ 10.1680/geot.1989.39.2.189.

Chehade, H. A., Dias, D., Sadek, M., Jenck, O. \& Chehade, F. H. (2019). Seismic analysis of geosynthetic-reinforced retaining wall in cohesive soils. Geotext. Geomembr. 47, No. 3, 315-326, https://doi.org/10.1016/j.geotexmem.2019.02.003.

Chehade, H. A., Dias, D., Sadek, M., Jenck, O. \& Chehade, F. H. (2020). Upper bound seismic limit analysis of geosyntheticreinforced unsaturated soil walls. Geotext. Geomembr. 48, No. 4, 419-430, https://doi.org/10.1016/j.geotexmem.2020.02.001.
Chen, W. (1975). Limit analysis and soil plasticity. Amsterdam, the Netherlands: Elsevier.

Chen, Y., Gao, Y., Yang, S. \& Zhang, Z. (2018). Required unfactored geosynthetic strength of three-dimensional reinforced soil structures comprised of cohesive backfills. Geotext. Geomembr. 46, No. 6, 860-868, https://doi.org/10.1016/j.geotexmem.2018. 08.004 .

Damians, I. P., Bathurst, R. J., Josa, A., Lloret, A. \& Albuquerque, P. J. R. (2013). Vertical-facing loads in steelreinforced soil walls. J. Geotech. Geoenviron. Engng 139, No. 9, 1419-1432, https://doi.org/10.1061/(ASCE)GT. 1943-5606.0000874.

Davis, E. H. (1968). Theories of plasticity and failure of soil masses. In Soil mechanics: selected topics (ed. I.K. Lee), pp. 341-380. London, UK: Butterworths.

Ehrlich, M. \& Mirmoradi, S. H. (2013). Evaluation of the effects of facing stiffness and toe resistance on the behavior of GRS walls. Geotext. Geomembr. 40, 28-36, https://doi.org/10.1016/j.geotexmem.2013.07.012.

El-Emam, M. M. \& Bathurst, R. J. (2005). Facing contribution to seismic response of reduced-scale reinforced soil walls. Geosynth. Int. 12, No. 5, 215-238, https://doi.org/10.1680/gein.2005.12.5. 215.

Elias, V. E. \& Christopher, B. R. (2001). Mechanically stabilized earth walls and reinforced soil slopes: design and construction guidelines, FHWA-NHI-00-043. Washington, DC, USA: U.S. Department of Transportation, Federal Highway Administration.

Farrag, K., Abu-Farsakh, M. \& Morvant, M. (2004). Stress and strain monitoring of reinforced soil test wall. Transp. Res. Rec., $J$. Transp. Res. Board 1868, 89-99, https://doi.org/ 10.3141/1868-10.

Fishman, K. L., Desai, C. S. \& Sogge, R. L. (1993). Field behavior of instrumented geogrid soil reinforced wall. J. Geotech. Engng 119, No. 8, 1293-1307, https://doi.org/10.1061/(ASCE) 0733-9410(1993)119:8(1293).

González-Castejón, J. \& Smith, C. C. (2021). Optimised design of soil reinforcement layout. Géotechnique, https://doi.org/ 10.1680/jgeot.19.p.326.

Hatami, K. \& Bathurst, R. J. (2005). Development and verification of a numerical model for the analysis of geosynthethicreinforced soil segmental walls under working stress conditions. Can. Geotech. J. 42, No. 4, 1066-1085, https://doi.org/10.1139/ t05-040.

Ho, S. K. \& Rowe, R. K. (1996). Effect of wall geometry on the behaviour of reinforced soil walls. Geotext. Geomembr. 14, No. 10, 521-541, https://doi.org/10.1016/S0266-1144(97)83183-4.

Holtz, R. D. \& Lee, W. F. (2002). Internal stability analyses of geosynthetic reinforced retaining walls, No. WA-RD 532.1. Washington, DC, USA: U.S. Department of Transportation, Federal Highway Administration.

Huang, B., Bathurst, R. J., Hatami, K. \& Allen, T. M. (2010). Influence of toe restraint on reinforced soil segmental walls. Can. Geotech. J. 47, No. 8, 885-904, https://doi.org/10.1139/T10-002.

Ismeik, M. \& Guler, E. (1998). Effect of wall facing on the seismic stability of geosynthetic-reinforced retaining walls. Geosynth. Int. 5, No. 1-2, 41-53, https://doi.org/10.1680/gein.5.0113.

Jewell, R. A. (1990). Revised design charts for steep reinforced slopes. In Proceedings of reinforced embankments, theory and practice (ed. D. A. Shercliff), pp. 1-30. London, UK: Thomas Telford.

Jewell, R. A. (1996). Soil reinforcement with geotextiles. London, UK: Thomas Telford.

Koerner, R. M. (2005). Designing with geosynthetics, 5th edn. Upper Saddle River, NJ, USA: Pearson Prentice Hall.

Koerner, R. M. \& Koerner, G. R. (2011). The importance of drainage control for geosynthetic reinforced mechanically stabilized earth walls. J. Geoengng 6, No. 1, 3-13, https://doi. org/10.6310/jog.2011.6(1).1.

Koerner, R. M. \& Koerner, G. R. (2018). An extended data base and recommendations regarding 320 failed geosynthetic reinforced mechanically stabilized earth (MSE) walls. Geotext. Geomembr. 46, No. 6, 904-912, https://doi.org/10.1016/j.geotexmem.2018. 07.013.

Leshchinsky, D. (2007). Discussion on the influence of facing stiffness on the performance of two geosynthetic reinforced soil 
retaining walls. Can. Geotech. J. 44, No. 12, 1479-1482, https://doi.org/10.1139/T07-102.

Leshchinsky, D., Ling, H. \& Hanks, G. (1995). Unified design approach to geosynthetic reinforced slopes and segmental walls. Geosynth. Int. 2, No. 5, 845-881, https://doi.org/10.1680/gein.2. 0039.

Leshchinsky, D., Zhu, F. \& Meehan, C. L. (2010). Required unfactored strength of geosynthetic in reinforced earth structures. J. Geotech. Geoenviron. Engng 136, No. 2, 281-289, https://doi.org/10.1061/(ASCE)GT.1943-5606.0000209.

Leshchinsky, D., Ebrahimi, S., Vahedifard, F. \& Zhu, F. (2012). Extension of Mononobe-Okabe approach to unstable slopes. Soils Found. 52, No. 2, 239-256, https://doi.org/10.1016/j.sandf. 2012.02.004.

Leshchinsky, D., Leshchinsky, B. \& Leshchinsky, O. (2017). Limit state design framework for geosynthetic-reinforced soil structures. Geotext. Geomembr. 45, No. 6, 642-652, https://doi. org/10.1016/j.geotexmem.2017.08.005.

Li, Z. W. \& Yang, X. L. (2018). Active earth pressure for soils with tension cracks under steady unsaturated flow conditions. Can. Geotech. J. 55, No. 12, 1850-1859, https://doi.org/10.1139/ cgj-2017-0713.

Li, Z. W. \& Yang, X. L. (2019). Active earth pressure for retaining structures in cohesive backfills with tensile strength cut-off. Comput. Geotech. 110, 242-250, https://doi.org/10.1016/ j.compgeo.2019.02.023.

Ling, H. I. \& Leshchinsky, D. (2003). Finite element parametric study of the behavior of segmental block reinforced-soil retaining walls. Geosynth. Int. 10, No. 3, 77-94, https://doi.org/ 10.1680/gein.2003.10.3.77.

Ling, H. I., Leshchinsky, D. \& Chou, N. N. S. (2001). Post-earthquake investigation on several geosynthetic-reinforced soil retaining walls and slopes during the Ji-Ji earthquake of Taiwan. Soil Dyn. Earthq. Engng 21, No. 4, 297-313, https:/ doi.org/10.1016/S0267-7261(01)00011-2.

Michalowski, R. L. (1997). Stability of uniformly reinforced slopes. J. Geotech. Geoenviron. Engng 123, No. 6, 546-556, https:// doi.org/10.1061/(ASCE)1090-0241(1997)123:6(546).

Michalowski, R. L. (2013). Stability assessment of slopes with cracks using limit analysis. Can. Geotech. J. 50, No. 10, 1011-1021, https://doi.org/10.1139/cgj-2012-0448.

Michalowski, R. L. \& Zhao, A. (1995). Continuum versus structural approach to stability of reinforced soil. J. Geotech. Engng 121, No. 2, 152-162, https://doi.org/10.1061/(ASCE)0733-9410 (1995)121:2(152).

Mirmoradi, S. H. \& Ehrlich, M. (2015). Numerical evaluation of the behavior of grs walls with segmental block facing under working stress conditions. J. Geotech. Geoenviron. Engng 141, No. 3, 04014109, https://doi.org/10.1061/(ASCE)GT.1943-5606. 0001235.

Muraro, S., Madaschi, A. \& Gajo, A. (2015). Passive soil pressure on sloping ground and design of retaining structures for slope stabilisation. Géotechnique 65, No. 6, 507-516, https://doi.org/ 10.1680/geot.14.P.211.

NCMA (2010). Design manual for segmental retaining walls (ed. M. Bernardi), 3rd edn. Herndon, VA, USA: National Concrete Masonry Association.

Perry, J. (1994). A technique for defining non-linear shear strength envelopes, and their incorporation in a slope stability method of analysis. Q. J. Engng Geol. 27, No. 3, 231-241, https://doi.org/ 10.1144/gsl.qjegh.1994.027.p3.04.

Porbaha, A. \& Goodings, D. J. (1997). Laboratory investigation of nonuniformly reinforced soil-retaining structures. Geotech. Test. J. 20, No. 3, 289-295, https://doi.org/10.1520/gtj19970004.

Porbaha, A., Zhao, A., Kobayashi, M. \& Kishida, T. (2000). Upper bound estimate of scaled reinforced soil retaining walls. Geotext.
Geomembr. 18, No. 6, 403-413, https://doi.org/10.1016/ S0266-1144(99)00036-9.

Potts, D. M. \& Fourie, A. B. (1986). A numerical study of the effects of wall deformation on earth pressures. Int. J. Numer. Analyt. Methods Geomech. 10, No. 4, 383-405, https://doi.org/10.1002/ nag. 1610100404.

Potts, D. M., Kovacevic, N. \& Vaughan, P. R. (1997). Delayed collapse of cut slopes in stiff clay. Géotechnique 47, No. 5, 953-982, https://doi.org/10.1680/geot.1997.47.5.953.

Riccio, M., Ehrlich, M. \& Dias, D. (2014). Field monitoring and analyses of the response of a block-faced geogrid wall using fine-grained tropical soils. Geotext. Geomembr. 42, No. 2, 127-138, https://doi.org/10.1016/j.geotexmem.2014.01.006.

Salem, M. A., Hammad, M. A. \& Amer, M. I. (2018). Field monitoring and numerical modeling of $4.4 \mathrm{~m}$-high mechanically stabilized earth wall. Geosynth. Int. 25, No. 5, 545-559, https://doi.org/10.1680/jgein.18.00027.

Sawicki, A. (1983). Plastic limit behavior of reinforced earth. $J$. Geotech. Engng 109, No. 7, 1000-1005, https://doi.org/10.1061/ (ASCE)0733-9410(1983)109:7(1000).

Sloan, S. W. (2013). Geotechnical stability analysis. Géotechnique 63, No. 7, 531-571, https://doi.org/10.1680/geot.12.RL.001.

Suah, P. G. \& Goodings, D. J. (2001). Failure of geotextile-reinforced vertical soil walls with marginal backfill. Transp. Res. Rec., J. Transp. Res. Board 1772, No. 1, 183-189, https://doi.org/ $10.3141 / 1772-22$.

Take, W. A. \& Bolton, M. D. (2011). Seasonal ratcheting and softening in clay slopes, leading to first-time failure. Géotechnique 61, No. 9, 757-769, https://doi.org/10.1680/geot.9.P.125.

Tatsuoka, F., Tateyama, M., Uchimura, T. \& Koseki, J. (1998). Geosynthetic-reinforced soil retaining walls as important permanent structures. Geosynth. Int. 4, No. 2, 81-136, https:// doi.org/10.1680/gein.4.0090.

Thusyanthan, N. I., Take, W. A., Madabhushi, S. P. G. \& Bolton, M. D. (2007). Crack initiation in clay observed in beam bending. Géotechnique 57, No. 7, 581-594, https:/doi.org/10.1680/geot. 2007.57.7.581.

Utili, S. (2013). Investigation by limit analysis on the stability of slopes with cracks. Géotechnique 63, No. 2, 140-154, https://doi. org/10.1680/geot.11.P.068.

Utili, S. \& Abd, A. H. (2016). On the stability of fissured slopes subject to seismic action. Int. J. Numer. Analyt. Methods Geomech. 40, No. 5, 785-806, https://doi.org/10. 1002/nag.2498.

Utili, S. \& Nova, R. (2007). On the optimal profile of a slope. Soils Found. 47, No. 4, 717-729, https://doi.org/10.3208/sandf. 47.717.

Vahedifard, F., Leshchinsky, B. A., Sehat, S. \& Leshchinsky, D. (2014). Impact of cohesion on seismic design of geosyntheticreinforced earth structures. J. Geotech. Geoenviron. Engng 140, No. 6, 04014016, https://doi.org/10.1061/(ASCE)GT.1943-5606. 0001099.

Wu, J. T. H. \& Payeur, J. P. (2015). Connection stability analysis of segmental geosynthetic reinforced soil (GRS) walls. Transpn Infrastruct. Geotechnol. 2, No. 1, 1-17, https://doi.org/10. 1007/s40515-014-0013-4.

Xie, Y., Leshchinsky, B. \& Yang, S. (2016). Evaluating reinforcement loading within surcharged segmental block reinforced soil walls using a limit state framework. Geotext. Geomembr. 44, No. 6, 832-844, https://doi.org/10.1016/j.geotexmem.2016. 06.010 .

Zhang, W., Chen, J. F. \& Yu, Y. (2019). Influence of toe restraint conditions on performance of geosynthetic-reinforced soil retaining walls using centrifuge model tests. Geotext. Geomembr. 47, No. 5, 653-661, https://doi.org/10.1016/j.geotexmem.2019.103469. 